\title{
A Laboratory Earthquake-Based Stochastic Seismic Source Generation Algorithm for Strike-Slip Faults and its Application to the Southern San Andreas Fault
}

\author{
by Hemanth Siriki, Harsha S. Bhat, Xiao Lu, and Swaminathan Krishnan
}

\begin{abstract}
There is a sparse number of credible source models available from largemagnitude past earthquakes. A stochastic source-model-generation algorithm thus becomes necessary for robust risk quantification using scenario earthquakes. We present an algorithm that combines the physics of fault ruptures as imaged in laboratory earthquakes with stress estimates on the fault constrained by field observations to generate stochastic source models for large-magnitude $\left(M_{\mathrm{w}} 6.0-8.0\right)$ strike-slip earthquakes. The algorithm is validated through a statistical comparison of synthetic groundmotion histories from a stochastically generated source model for a magnitude 7.90 earthquake and a kinematic finite-source inversion of an equivalent magnitude past earthquake on a geometrically similar fault. The synthetic dataset comprises threecomponent ground-motion waveforms, computed at 636 sites in southern California, for 10 hypothetical rupture scenarios (five hypocenters, each with two rupture directions) on the southern San Andreas fault. A similar validation exercise is conducted for a magnitude 6.0 earthquake, the lower magnitude limit for the algorithm. Additionally, ground motions from the $M_{\mathrm{w}} 7.9$ earthquake simulations are compared against predictions by the Campbell-Bozorgnia Next Generation Attenuation relation, as well as the ShakeOut scenario earthquake. The algorithm is then applied to generate 50 source models for a hypothetical magnitude 7.9 earthquake originating at Parkfield, California, with rupture propagating from north to south (toward Wrightwood), similar to the 1857 Fort Tejon earthquake. Using the spectral element method, three-component ground-motion waveforms are computed in the Los Angeles basin for each scenario earthquake and the sensitivity of ground-shaking intensity to seismic source parameters (such as the percentage of asperity area relative to the fault area, rupture speed, and rise time) is studied.
\end{abstract}

Online Material: Figures of source and simulated peak ground motions for an $M_{\mathrm{w}} 6.05$ scenario on the southern San Andreas fault, and table of $V_{S 30}$ and basin depth at stations.

Introduction

Rupture-to-rafters simulations offer an alternative (and perhaps more realistic) approach for risk quantification and design of new structures (Krishnan et al., 2006, 2011). Generating stochastic seismic source models for these simulations is a crucial step, given the limited number of credible source models from large historical earthquakes. The seismic source model is a mathematical representation of the earthquake rupture process. Two types of source models are used in earthquake physics:

1. Kinematic models prescribe the spatial and temporal evolution of the rupture speed, the slip, and the slip velocity on the fault, inferred from seismic, geodetic, and geological observations.

2. Dynamic models prescribe the fault prestress, fracture energy, and stress drop. An earthquake is nucleated at a point in the model by artificially increasing the prestress to a value greater than the shear strength. The rupture process is then allowed to evolve dynamically as dictated by an assumed fault friction law. The development of dynamic source models is an active area of research in earthquake source physics (e.g., Madariaga and Olsen, 2002; Schmedes et al., 2010; Bizzarri, 2011). 
(a)

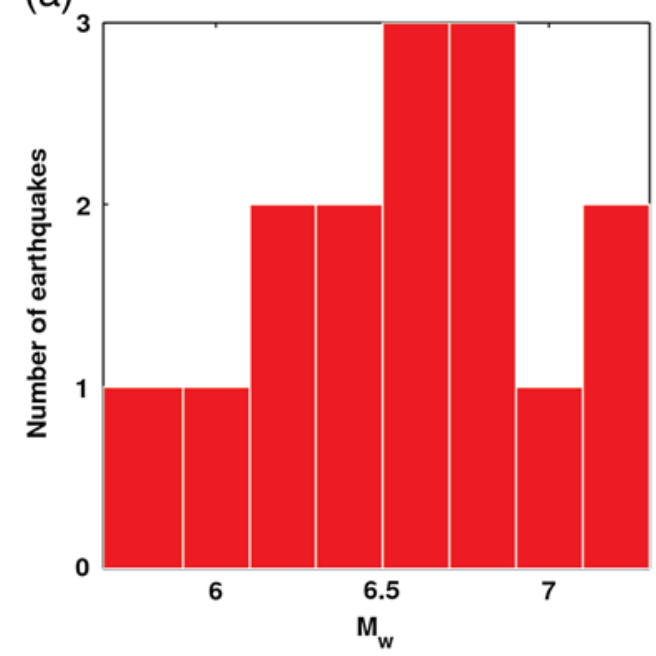

(b)

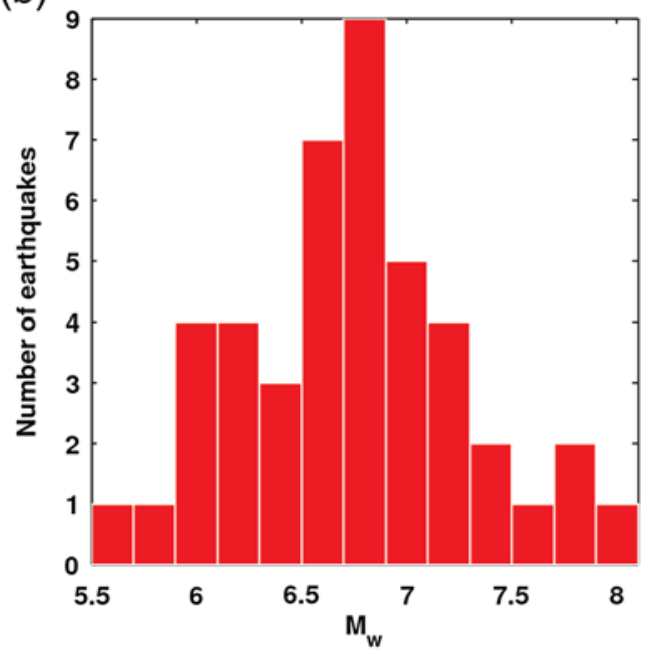

Figure 1. Magnitudes of past earthquakes considered by (a) Somerville et al. (1999) and (b) Mai and Beroza (2002) for determining the spectral properties of the slip distribution on the fault. Source mechanisms of these earthquakes are not limited to strike slip, but include reverse, thrust, etc. Note the sparse number of large-magnitude $\left(M_{\mathrm{w}} \geq 7.0\right)$ earthquakes included in either study. The color version of this figure is available only in the electronic edition.

Although dynamic source models may better characterize earthquake source physics and there are efforts underway to validate them against empirical data (e.g., Dalguer et al., 2008; Harris et al., 2009; Olsen et al., 2009; Andrews and Barall, 2011; Shi and Day, 2013; Baumann and Dalguer, 2014), the theory is more complex and less mature when compared with kinematic source modeling. (For example, the state of stress in the earth and the fault friction law are not known; they are not as well constrained as kinematic source parameters such as slip.) Here, we represent an earthquake source using a kinematic model. Kinematic source description involves dividing the fault rupture plane(s) into a number of smaller subevents. Each subevent (considered as a point source) is characterized by three parameters: slip, rupture speed, and slip velocity-time function. Brune (1970) proposed one of the earliest earthquake source models, in which near- and far-field displacement spectra are calculated from a fault dislocation model accelerated by an effective stress. Significant progress has been made in kinematic source modeling since then, with the help of data collected by modern seismic networks (Zeng et al., 1994; Hartzell et al., 1999; Somerville et al., 1999; Mai and Beroza, 2002; Nielsen and Madariaga, 2003; Guatteri et al., 2004; Tinti et al., 2005; Lavallée et al., 2006; Liu et al., 2006; Aagaard, Graves, Rodgers, et al., 2010; Aagaard, Graves, Schwartz, et al., 2010; Graves and Pitarka, 2010). We start with a brief description of current approaches to prescribing the three source parameters for each subevent.

\section{Slip Distribution}

Spatial variation of kinematic slip in a rupture is perhaps the best understood amongst the three source parameters. This is partly due to the fact that surface slip can be con- strained in a finite-source inversion of an earthquake using geodetic observations. Rupture speed and slip velocity-time function, on the other hand, are inferred completely through inversions. The power spectral density (PSD) of the 2D slip distribution from these inversions typically decays with wavenumber according to a power law. On this basis, a PSD function, inferred from finite-source inversion of past earthquakes, could be inverted back to the spatial domain to produce a stochastic slip model (e.g., Somerville et al., 1999; Mai and Beroza, 2002). Because finite-source inversions are typically able to resolve longer wavelengths only, their PSDs do not properly characterize the spectral drop-off with wavenumber. Graves and Pitarka (2010) overcome this deficiency by augmenting the long-wavelength portion of the PSDs from finite-source inversions (or uniform/random slip distributions) with a bandlimited PSD function that accurately captures the spectral decay inferred from seismic data. It should be noted that in developing the PSD function, slip inversions of only a limited number of large-magnitude earthquakes were used (e.g., Fig. 1), and the slip models are often interpolated to facilitate a direct comparison. In a study of seven earthquakes, including the 1994 Northridge earthquake, Lavallee et al. (2006) discussed the negative effects of this interpolation on PSD decay. Moreover, this approach anchors the sources to a specific power-spectral decay and may not capture the degree of variability perhaps inherent to seismic sources.

An alternate approach is to stochastically generate spatial distribution of slips for an earthquake of given magnitude and accept or reject each model by one of two methods:

1. comparing spectra of the resulting synthetic ground motions (assuming a rupture speed and slip velocity-time function distribution) against that of recorded ones (e.g., Zeng et al., 1994) or 
2. comparing the spectral decay as a function of wavenumber against the broad range of the corresponding decays found in finite-source inversions of past earthquakes.

Whereas in the former approach, the spectra of synthetic ground motions are influenced by the choice of rupture speed, slip velocity-time function, Green's function, etc., the latter has no such concerns. Accordingly, the latter approach is adopted here. Our algorithm divides the rupture area recursively along length, until each daughter segment has a dimensional aspect ratio close to unity. The mean slip on each daughter segment is characterized using lognormal probability distributions. The mean and standard deviation of these distributions depend upon the magnitude of its parent segment. Slip on each daughter segment is assigned a value that is a single realization of the corresponding probability distribution, with the slip vector oriented along strike (i.e., rake $=180^{\circ}$ ). To introduce slip variation along depth, each (approximately square) daughter segment is subdivided into four segments using one subdivision along depth and one along length. The assignment of slip for this penultimate generation of daughter segments is based on the same method as the previous generations of daughter segments. Finally, these penultimate generation segments are subdivided along length and depth to the resolution needed for wave propagation simulations. Slips are assigned to the final generation of segments as realizations of the lognormal probability distribution corresponding to the magnitude of the parent segment from the penultimate generation. A filter is applied to smoothen the resulting slip distribution, eliminating sharp spatial variations. Additionally, at each step, the mean slips are scaled linearly to that of the parent segment such that the net seismic moment $M_{0}$ is conserved. The resulting slip distribution is accepted if the average power spectra, along the length and the depth of the rupture, decay with wavenumber according to a power law with decay coefficient between 2.0 and 4.0. This is the range of values for the decay observed in finite-source inversions of past earthquakes (e.g., Somerville et al., 1999; Mai and Beroza, 2002). The use of 1D spectra along length and depth rather than a 2D spectrum over the area of rupture is based on the assumption that slip along fault is statistically independent of slip along depth. Although this assumption may not strictly hold true, the use of a circular PSD criterion for model acceptance is not likely to be significantly different from the use of two 1D spectra along length and depth (Lavallée et al., 2006).

\section{Rupture Speed Distribution}

The initiation time of slip at any given location along the rupture depends upon the rupture speed $V_{\mathrm{r}}$. Rupture speed can have a significant influence on the character of the radiated seismic waves, the resulting ground motions, and the impact on the built environment. Even though theoretical models (e.g., Burridge, 1973; Andrews, 1976) have shown that ruptures could travel at speeds higher than the Rayleigh-wave speed, rupture speeds in ground-motion simulations have tra- ditionally been assumed to be lower. This is due, in part, to the sparsity of such strong ground motion data. However, evidence from recent earthquakes, such as the $1999 M_{\mathrm{w}} 7.6$ Izmit (e.g., Bouchon et al., 2002), the $2001 M_{\mathrm{w}} 7.8$ Kunlun (e.g., Bouchon and Vallée, 2003; Bhat et al., 2007), the 2002 $M_{\mathrm{w}} 7.9$ Denali (e.g., Dunham and Archuleta, 2004; Frankel, 2004), and the $1979 M_{\mathrm{w}} 6.4$ Imperial Valley (e.g., Archuleta, 1984; Das, 2010) earthquakes, point to rupture speeds exceeding the Rayleigh-wave speed.

Based in part on this evidence, several new models have been developed with an underlying principle that the secant rupture speed (the average rupture speed from the hypocenter to a given subfault location) or local rupture speed is correlated with slip on the fault (e.g., Guatteri et al., 2004; Liu et al., 2006; Aagaard, Graves, Rodgers, et al., 2010; Aagaard, Graves, Schwartz, et al., 2010; Graves and Pitarka, 2010; Song and Somerville, 2010; Song et al., 2014). Others correlate rupture initiation with slip (e.g., Graves and Pitarka, 2010). However, Schmedes et al. (2010) found no evidence for such correlation from dynamic rupture models of 315 earthquakes. They further cautioned that assuming any such correlation could lead to overprediction of simulated ground motions. In addition to field observations and theoretical models, laboratory earthquakes have yielded important insights into the fault rupture process. Stable pulse-like ruptures have been realized in the laboratory under controlled conditions (Rosakis et al., 1999, 2007; Lu, 2009; Lu et al., 2010; Mello et al., 2010). Both sub-Rayleigh and supershear ruptures have been realized. The sub-Rayleigh ruptures have been observed to propagate at speeds in the vicinity of $0.87 V_{S}$, in which $V_{S}$ is the shear-wave speed in the medium. Under special normal stress and fault roughness conditions, the ruptures have been observed to transition to supershear speeds in the vicinity of $1.67 \mathrm{~V}_{S}$.

In our source representation, we assume that all ruptures initiate at a sub-Rayleigh speed of $0.87 V_{S}$. Using estimates of prestress on the fault from paleoseismic, focal mechanisms, borehole breakouts, and other in situ observations cataloged in the World Stress Map (WSM) project (Heidbach et al., 2008), we assess whether conditions exist for rupture to transition to supershear speeds as it progresses along the fault. If such conditions do exist for any subevent along the rupture, we prescribe a rupture speed of $1.67 V_{S}$ for that subevent. We noted previously when discussing dynamic source models that the state of stress in the earth is not known accurately. Yet, we continue to use estimates of the same in characterizing our kinematic source models. This is justifiable, because only the rupture speed in kinematic source models is dependent upon the state of stress. On the other hand, the evolution of all three source parameters (slip, slip velocity, and rupture speed) in dynamic source models are affected by the state of stress.

\section{Slip Velocity-Time Function}

The slip velocity-time function describes the temporal evolution of slip during an earthquake and is characterized 
by slip magnitude, rise time (time taken for peak slip to be attained), and peak time (time taken for peak slip velocity to be attained). Variation of slip velocity with time in a source model affects the frequency and amplitude characteristics of the resulting ground motions. It is specified either as a single function (single time window) or as a series of overlapping time-shifted functions (multiple time windows). Commonly assumed functional forms include Gaussian, triangular, trigonometric, and modified Yoffe (Tinti et al., 2005). Function coefficients are typically determined from dynamic rupture simulations (e.g., Cotton and Campillo, 1995; Guatteri et al., 2004; Tinti et al., 2005; Liu et al., 2006) or finite-source inversions of past earthquakes (e.g., Hartzell et al., 1996; Somerville et al., 1999). Unfortunately, dynamic rupture simulations have been seen to be quite sensitive to the choice of modeling parameters, making it difficult to constrain these coefficients. Furthermore, seismic data that could be useful in determining these coefficients are rather sparse. Thus, there is limited understanding of these source characteristics. Laboratory earthquakes could serve to bridge this knowledge gap as the slip velocity-time function can be directly measured in the laboratory.

In the laboratory earthquakes generated by $\mathrm{Lu}$ (2009) and $\mathrm{Lu}$ et al. (2010), rise time (measured in $\mu \mathrm{s}$ ) was found to be linearly correlated with slip (measured in $\mu \mathrm{m}$ ), as shown in Figure 2. The rise times shown are the basal widths of the best-fitting isosceles triangles to the slip velocity-time functions measured in the laboratory. This is in agreement with dynamic rupture studies (e.g., Schmedes et al., 2010) and is similar to Graves and Pitarka (2010), in which they postulate rise time being proportional to the square root of the slip. We fit a lognormal probability density function (PDF) to the slip to rise-time ratio measured in the laboratory earthquakes. Assuming self-similarity of the slip-to-rise-time ratio between the laboratory scale and the earth scale, we equate the mean and variance of this ratio at the earth scale to that observed in the laboratory. Independent realizations of this PDF are assigned as the slip-to-rise-time ratios for all the subfaults comprising the rupture. A slip proportional rise time is thus prescribed to each segment. This incorporates the physics of temporal characteristics of slip as we best know it. It should be noted that Andrews and Barall (2011) make a comparable self-similarity assumption. They assume that the ratio of initial shear stress to the initial normal stress on the fault is scale independent and that the mean and variance of a PDF describing this ratio are scale invariant.

\section{Methodology}

\section{Slip Distribution}

For a target earthquake magnitude $M_{\mathrm{w}}$, the rupture area $A$ of a stochastic source model is estimated using the Hanks and Bakun $(2002,2008)$ relationship given by

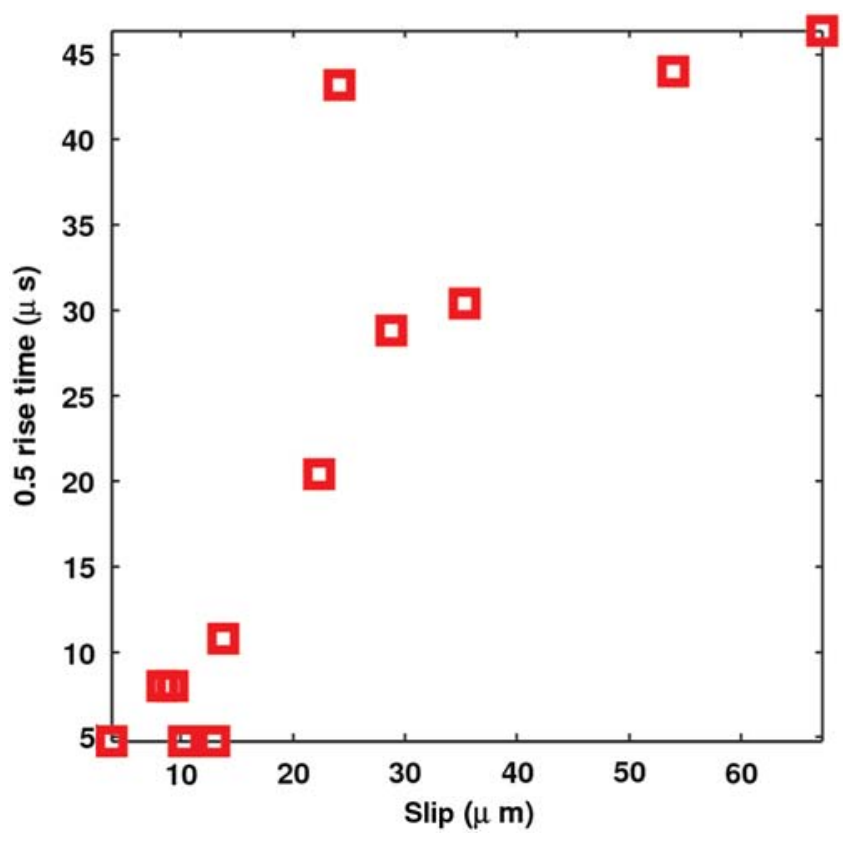

Figure 2. Rise time plotted as a function of slip observed in laboratory earthquakes (Lu, 2009; Lu et al., 2010). The correlation between the two is in agreement with dynamic rupture studies conducted by Schmedes et al. (2010). The color version of this figure is available only in the electronic edition.

$$
A=\left\{\begin{array}{ll}
10^{M_{\mathrm{w}}-3.98} & A \leq 537 \mathrm{~km}^{2} \\
10^{(3 / 4)\left(M_{\mathrm{w}}-3.07\right)} & A>537 \mathrm{~km}^{2}
\end{array} .\right.
$$

With the area of rupture known and the seismogenic depth $d$ inferred from seismicity on the fault, the length of rupture $l$ can be determined. If $d$ exceeds $l$, the rupture dimensions are recalculated assuming a square rupture area (i.e., $l=d$ ). Seismic moment $M_{0}$ and mean slip $\bar{D}$ of the earthquake are estimated from magnitude $M_{\mathrm{w}}$ using

$$
M_{0}=G A \bar{D}=10^{(3 / 2) M_{\mathrm{w}}+10.7},
$$

in which $G$ is the average shear modulus of the earth $(\sim 30 \mathrm{GPa})$. To arrive at a realistic slip distribution with this mean slip, we recursively divide the rupture area lengthwise in half, each parent segment being subdivided into two daughter segments. This segmentation is continued until each fault segment attains a dimensional aspect ratio close to unity. To develop a credible methodology to assign realistic slips to these segments, we have carefully studied finite-source inversions of 56 past strike-slip earthquakes (see Data and Resources for details) with magnitude $M_{\mathrm{w}} 6.0-8.0$. We observe that a series of lognormal PDFs can be used to reasonably describe the slip distribution in these sources. Furthermore, the standard deviation of lognormal PDF fits to the slip distribution in these models scales linearly with their magnitudes (Fig. 3). This linear scaling can be expressed by the regression relation

$$
\sigma=1.1827 M_{\mathrm{w}}-7.0754
$$




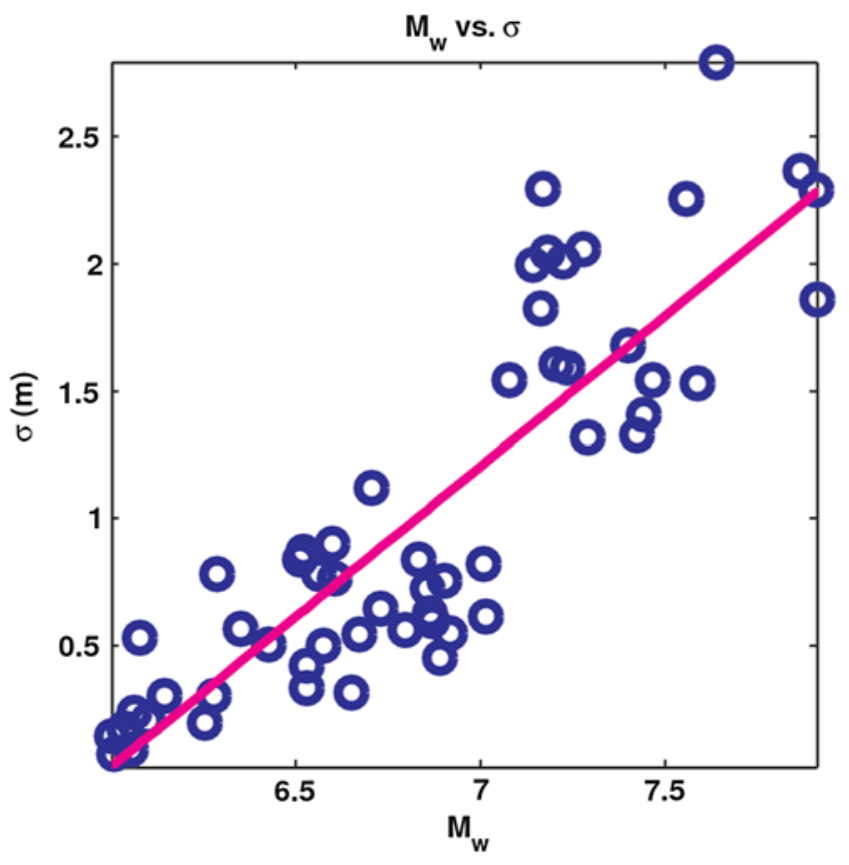

Figure 3. The circles show the standard deviation $\sigma$ of lognormal probability density function (PDF) fits to the slip distribution from finite-source inversions of 56 strike-slip earthquakes as a function of earthquake magnitude $M_{\mathrm{w}}$. The solid line is the best-fitting linear least-squares fit described by equation (3). The color version of this figure is available only in the electronic edition.

Now, from the parent segment magnitude and equation (3), we determine the standard deviation of the lognormal PDF that is to be used to characterize the slip of the daughter segments. The mean for this PDF is taken to be the average slip of the parent segment. Two independent realizations of this PDF are generated and assigned as the mean slips on the two daughter segments. They are subsequently scaled uniformly such that the sum of the seismic moments of the daughter segments matches that of the parent segment. If parent segment $M_{\mathrm{w}}$ is less than 6.0 (the lower magnitude limit in Fig. 3), the standard deviation corresponding to $M_{\mathrm{w}} 6.0$ is used.

To introduce variation of slip along the depth of the fault, each segment is subdivided into four daughter segments in the penultimate step, two along length and two along depth. Random mean slips are assigned as before. In the final step, each fault segment is further discretized to the resolution required for generating the desired highest frequency wave in groundmotion simulations. Slip assignment is based on independent realizations of a lognormal PDF with the mean slip and the standard deviation determined from equations (2) and (3), respectively, both using the magnitude of the parent segment. Finally, a unit 2D filter that is Gaussian along length and parabolic along depth is applied to smoothen the slip distribution (Fig. 4). Dimensions of the filter are $d$ and $3 / 4 d$ along length and depth, respectively. To ensure that maximum moment release occurs within the upper-third portion of the fault (Fialko et al., 2005), the parabola has a peak at two-thirds height from the bottom. The ordinate at the bottom of the filter is assigned

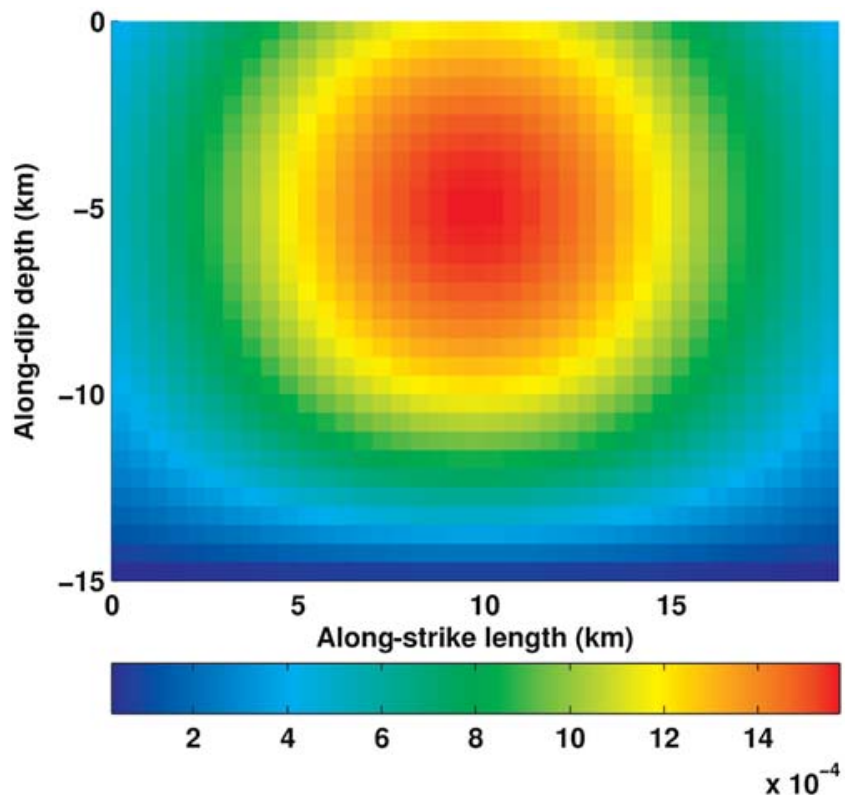

Figure 4. Plane view of the moment-preserving filter used to smoothen the slip distribution. The filter function is Gaussian along fault length (with width $d$ ) and parabolic along fault depth (with width $3 / 4 d$ ), in which $d$ is the depth of rupture. The parabola has a zero ordinate at the bottom and a peak at two-thirds height from the bottom. The color version of this figure is available only in the electronic edition.

zero value to ensure zero moment release below the seismogenic depth.

For example, suppose a stochastic source model is to be generated for a magnitude $M_{\mathrm{w}} 7.9$ earthquake on the San Andreas fault. From equation (1), the rupture area is $4200 \mathrm{~km}^{2}$. The average seismogenic depth of the San Andreas fault may be assumed to be $20 \mathrm{~km}$ (i.e., rupture depth $d=20$ ) based on observations. Therefore, the length of the rupture $L$ is $210 \mathrm{~km}$. Average slip from equation (2) is $6.30 \mathrm{~m}$. Figure 5a shows the hierarchy level 1 model. Recursive division of the level 1 model along the fault length leads to hierarchy levels 2, 3, and 4 (Fig. 5b,c, and d, respectively). The average slips on the two daughter segments at hierarchy level 2 are drawn from a lognormal PDF with mean slip of $6.30 \mathrm{~m}$ and standard deviation of $2.26 \mathrm{~m}$ (from equation 3 corresponding to $M_{\mathrm{w}} 7.9$ ). To preserve the seismic moment, the average slips of the daughter segments are scaled to $6.65 \mathrm{~m}\left(M_{\mathrm{w}} 7.71\right)$ and $5.95 \mathrm{~m}\left(M_{\mathrm{w}} 7.68\right)$, respectively. The average slips on the first two daughter segments at hierarchy level 3 are drawn from a lognormal PDF with mean slip of $6.65 \mathrm{~m}$ and standard deviation of $2.05 \mathrm{~m}$ (from equation 3 corresponding to $\left.M_{\mathrm{w}} 7.71\right)$. Again, these are scaled to $3.83 \mathrm{~m}\left(M_{\mathrm{w}} 7.35\right)$ and $9.47 \mathrm{~m}\left(M_{\mathrm{w}} 7.62\right)$, respectively, to preserve moment. The two daughter segments at level 3 arising from the $M_{\mathrm{w}} 7.68$ parent segment have average slips of 5.91 and $5.99 \mathrm{~m}$ (realizations drawn from a lognormal PDF with mean 5.95 and standard deviation 2.01 and scaled to match moment of $M_{\mathrm{w}}$ 7.68). Similarly, hierarchy level 4 results in eight $\sim 20 \mathrm{~km}^{2}$ segments, with average slips of $3.40\left(M_{\mathrm{w}} 7.11\right), 4.27$ $\left(M_{\mathrm{w}} 7.18\right), 9.46\left(M_{\mathrm{w}} 7.41\right), 9.48\left(M_{\mathrm{w}} 7.41\right), 6.73\left(M_{\mathrm{w}} 7.31\right)$, $5.10\left(M_{\mathrm{w}} 7.23\right), 6.48\left(M_{\mathrm{w}} 7.30\right)$, and $5.51 \mathrm{~m}\left(M_{\mathrm{w}} 7.26\right)$. At the 
(a)

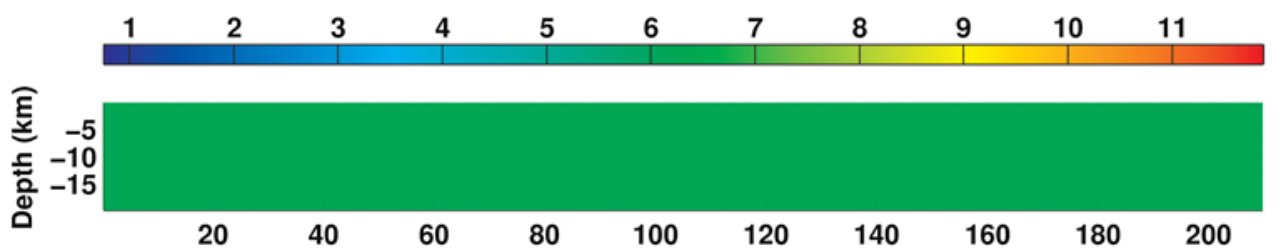

(b)

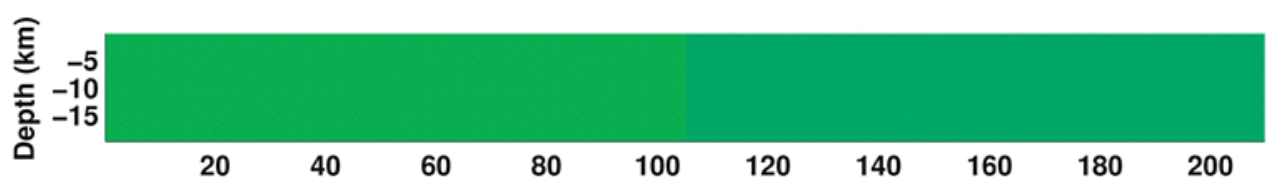

(c)

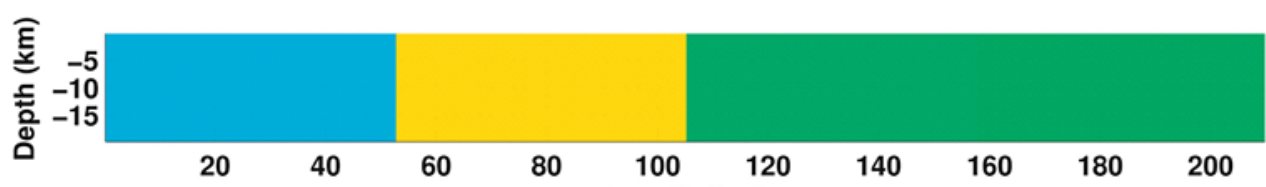

(d)

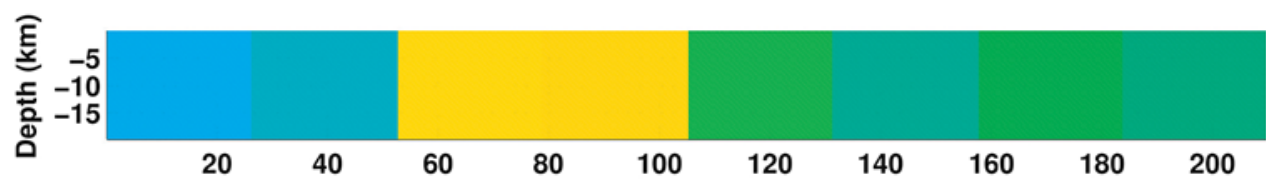

(e)

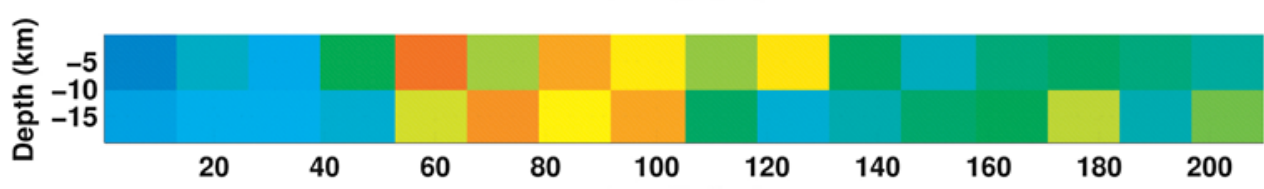

(f)

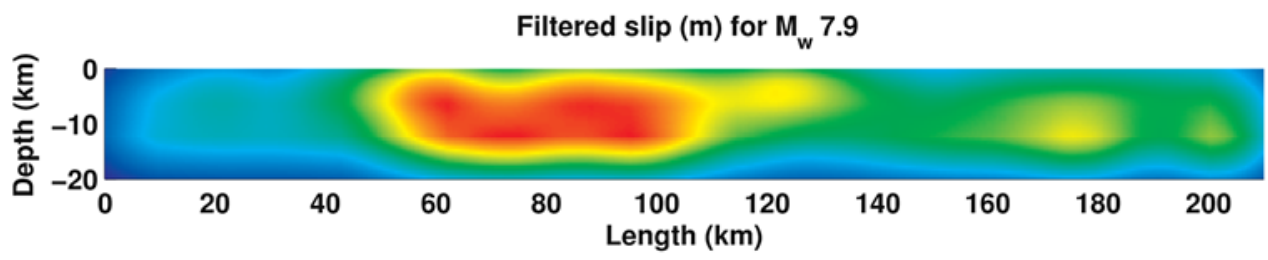

Figure 5. Application of the stochastic source-generation algorithm to an $M_{\mathrm{w}} 7.9$ strike-slip earthquake. Recursive divisions of fault area followed by assignment of random realizations of magnitude-dependent lognormal PDFs of slip lead to five hierarchical levels ([a] level 1 through [e] level 5) of the seismic source. The final step involves subdividing the parent segments into small daughter segments capable of producing the desired highest frequency wave in ground-motion simulations. Assignment of random realizations of magnitude-dependent lognormal PDFs of slip to these daughter segments along with a smoothing filter leads to (f) the final filtered slip distribution. The color version of this figure is available only in the electronic edition.

next hierarchy level, the fault is subdivided along both length and depth (Fig. 5e). Coincidentally, the area of $10 \mathrm{~km}^{2}$ segments at hierarchy level 5 corresponds approximately to a magnitude 6 rupture from equation (1), the lower magnitude limit of the finite-source inversions used in the development of equation (3). At the final step, the hierarchy level 5 segments are subdivided into $0.5 \mathrm{~km}^{2}$. This is the resolution needed to generate a $2 \mathrm{~s}$ wave in ground-motion simulations (Fig. 5f). The slips for each of these segments are generated as independent realizations of lognormal PDFs with mean slips from the scaled average slips of parent segments from hierarchy level 5 and standard deviations determined from equation (3) using the magnitudes corresponding to these parent segments. The powerspectral densities of the slip along fault length and depth as a function of the wavenumber are shown in Figure $6 a$ and $6 b$, respectively. The average PSD decays with wavenumber as a power law with decay coefficients of 2.24 and 2.13 along length and depth, respectively. Because these values lie between 2 and 4, this stochastic source model is an acceptable realization and can be reliably used for ground-motion simulations.

The normalized histograms of slip $(\mathrm{m})$ in a finite-source inversion model of the magnitude 7.9 Denali earthquake of 2002 (Krishnan et al., 2006) and one stochastic source realization using the outlined method are shown in Figure 7. The similarity in the two distributions (with the exception of the frequency of subfaults with zero slip) suggests that a series of lognormal PDFs can indeed be used to define slip distribution in stochastic source models. The large concentration of zero slip subfaults in the finite-source inversion model is due to the greater length assumed in the inversion $(\sim 290 \mathrm{~km})$ as compared with $\sim 210 \mathrm{~km}$ for the stochastic model.

\section{Rupture Speed $\left(V_{\mathrm{r}}\right)$}

Laboratory earthquakes (Rosakis et al., 2007; Lu, 2009; Lu et al., 2010; Mello et al., 2010) show the influence of initial fault shear stress on the rupture speed (in addition 
(a)

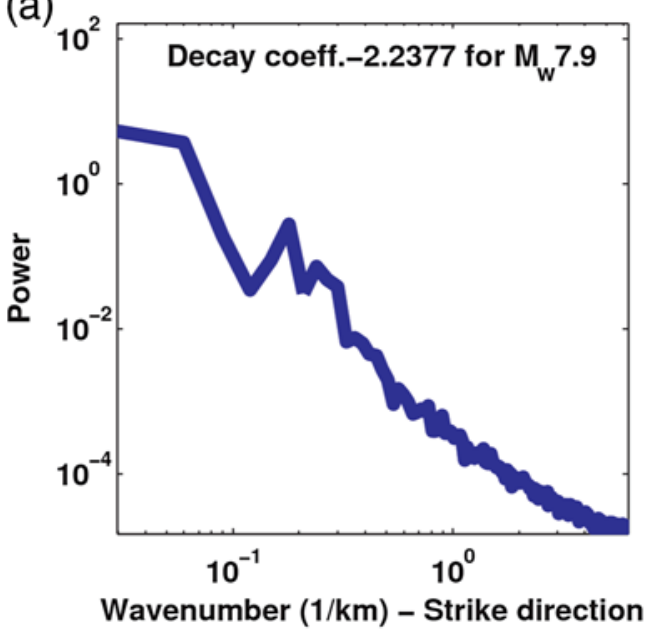

(b)

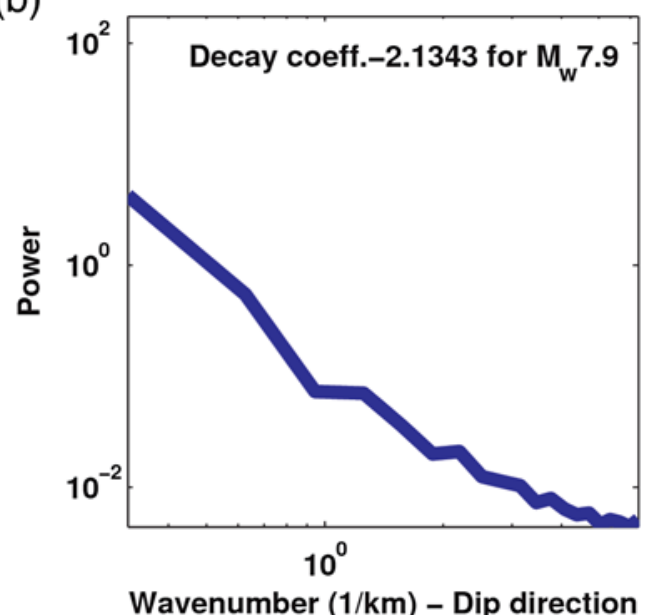

Figure 6. Power spectral density (PSD) of a stochastic slip realization along (a) strike and (b) dip directions, as shown in Figure $5 \mathrm{f}$ for an $M_{\mathrm{w}} 7.9$ earthquake. The color version of this figure is available only in the electronic edition.
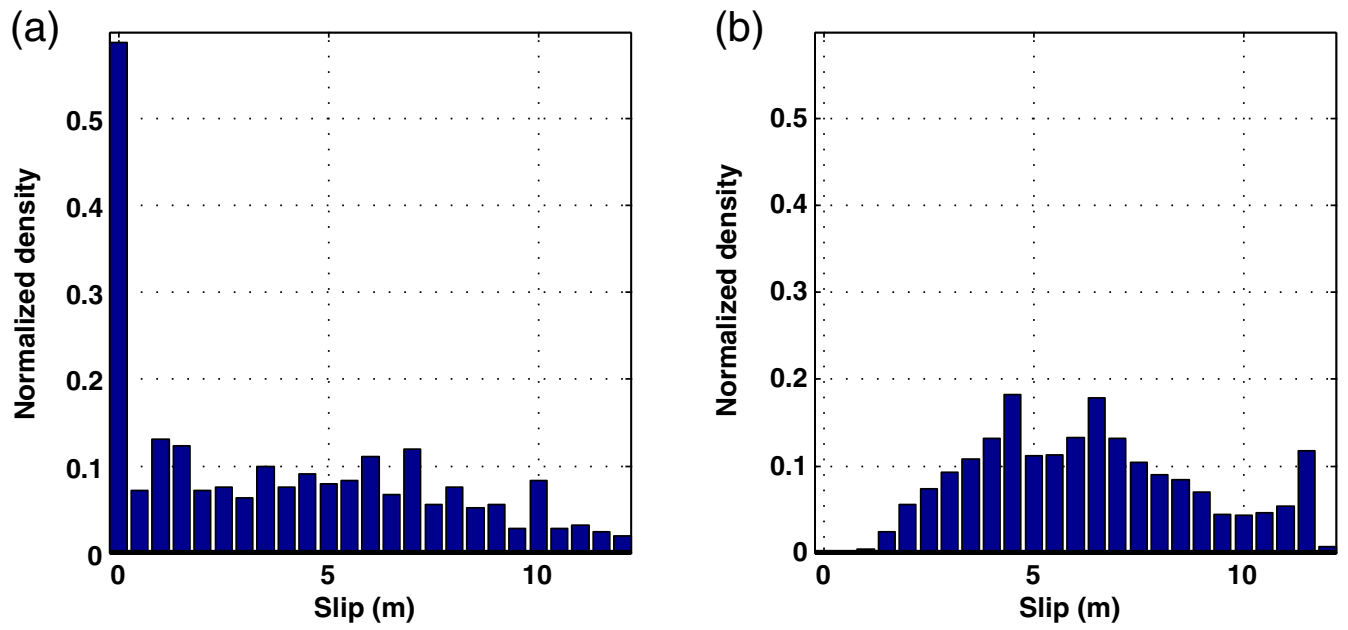

Figure 7. Normalized histograms of slip (m) of an $M_{\mathrm{w}} 7.9$ earthquake from (a) a finite-source inversion of the 2002 Denali earthquake and (b) one stochastic source realization using the outlined method. The color version of this figure is available only in the electronic edition.

to the influence of other parameters). Initial shear stress, in the case of a strike-slip fault, can be determined using the orientation $(\theta)$ between the maximum principal stress $\left(\sigma_{1}\right)$ and the fault strike. The maximum and minimum principal stresses $\left(\sigma_{1}\right.$ and $\left.\sigma_{3}\right)$ on a strike-slip fault lie on the plane perpendicular to that of the fault. The intermediate principal stress $\left(\sigma_{2}\right)$ is hydrostatic, acts normal to the fault plane, and varies linearly with fault depth. Evaluating $\theta$ along the fault forms an important step in estimating the initial shear stress $(\tau)$ and in further determining the rupture speed distribution for a seismic source.

The WSM project (Heidbach et al., 2008) compiles the azimuth of maximum principal stress $\left(\theta_{\mathrm{a}}\right)$ at near-fault locations worldwide. The angles are derived from field observations (including paleoseismic estimates of slip, borehole breakouts, and hydraulic fractures) and theoretical investigations (including focal mechanisms of past earthquakes).
Based on the quality of underlying data, an estimate of the maximum measurement error is also provided (Table 1).

To account for the uncertainty in the measurement of $\theta_{\mathrm{a}}$, we add a randomly generated fraction of the measurement error from Table 1 to the reported estimate of $\theta_{\mathrm{a}}$. We use this estimate of $\theta_{\mathrm{a}}$ in computing the orientation of the maximum principal stress $\sigma_{1}$ relative to the fault:

$$
\theta=180^{\circ}-\left|\phi-\theta_{\mathrm{a}}\right|,
$$

in which $\phi$ is the strike at the closest point on the fault. These near-fault data locations typically occur in clusters (e.g., data points on the southern San Andreas fault are clustered at five locations, as shown in Fig. 8).

We assume $\theta$ at each cluster location to be characterized by a lognormal distribution with mean equal to the arithmetic mean of $\theta$ for all the locations within the cluster and standard 
Table 1

Quality Factor and the Corresponding Error in Measurement of $\theta_{\mathrm{a}}$

\begin{tabular}{cc}
\hline Quality & Error \\
\hline A & $\pm 15^{\circ}$ \\
B & $\pm 20^{\circ}$ \\
C & $\pm 25^{\circ}$ \\
D & $\pm 40^{\circ}$ \\
E & Unreliable \\
\hline
\end{tabular}

deviation calculated from the cluster with the highest number of WSM data points. We further assume that $\theta$ is constant along fault depth, that is, rupture speed varies along fault length alone. All the subevents on the fault that lie in the zone tributary to a data cluster are assigned randomized $\theta s$ drawn from the corresponding lognormal distribution. All the subevents within distances equal to the seismogenic depth $d$ in a given tributary zone are assigned the same randomly generated realization of $\theta$. Assuming ambient stresses in the crust adjacent to the fault are maintained by the frictional stability of small, high-friction fractures and that fluid pressures in the crust are hydrostatic (Townend and Zoback, 2000, 2004; Zoback and Townend, 2001; Townend, 2006; J. Townend, personal comm., 2008), initial shear $(\tau)$ and normal $\left(\sigma_{\mathrm{n}}\right)$ stresses on the subevent are calculated using

$$
\begin{gathered}
\bar{\sigma}=\frac{\sigma_{1}+\sigma_{3}}{2} \simeq \sigma_{2}=\rho_{\mathrm{r}} g z ; p=\rho_{\mathrm{w}} g z ; \Delta \sigma=\frac{2 \mu_{p}(\bar{\sigma}-p)}{\sqrt{\mu_{p}^{2}+1}} ; \\
\text { and } \tau=\frac{\Delta \sigma}{2} \sin 2 \theta ; \sigma_{\mathrm{n}}=\bar{\sigma}-p-\frac{\Delta \sigma}{2} \cos 2 \theta,
\end{gathered}
$$

in which $p$ is the hydrostatic fluid pressure; $\bar{\sigma}$ and $\Delta \sigma$ are the mean and differential stress, respectively; $\rho_{\mathrm{r}}$ and $\rho_{\mathrm{w}}$ are the density of rock and water, respectively; $\tau$ and $\sigma_{\mathrm{n}}$ are the initial shear and normal stresses acting on the subfault, respectively; and $g$ is the acceleration due to gravity. In our algorithm, $z$ corresponds to half the seismogenic depth, and $\mu_{p}(=0.6)$ is the static Coulomb friction coefficient. Our assumption that the stress orientation is uniform with depth but variable along strike is primarily motivated by the lack of data along depth. If, in the future, such data become available, the algorithm could be modified to incorporate variations along depth as well.

Loading factor $(S)$ at any given location along the fault is calculated as

$$
S=\frac{\left(\tau_{p}-\tau_{r}\right)}{\left(\tau-\tau_{r}\right)}, \quad \tau_{p}=\mu_{p} \sigma_{n} ; \tau_{r}=\mu_{r} \sigma_{n},
$$

in which $\mu_{p}(=0.6)$ and $\mu_{r}(=0.1)$ (Goldsby and Tullis, 2002; Di Toro et al., 2004) are the static and dynamic friction coefficients, respectively, and $\tau_{p}$ and $\tau_{r}$ are the static and dynamic friction strength of the fault at that location, respectively. If $S \geq 1.77$, rupture is assumed to propagate at sub-Rayleigh speeds (Andrews, 1976), and a rupture speed of $0.87 V_{\mathrm{S}}$ is as-

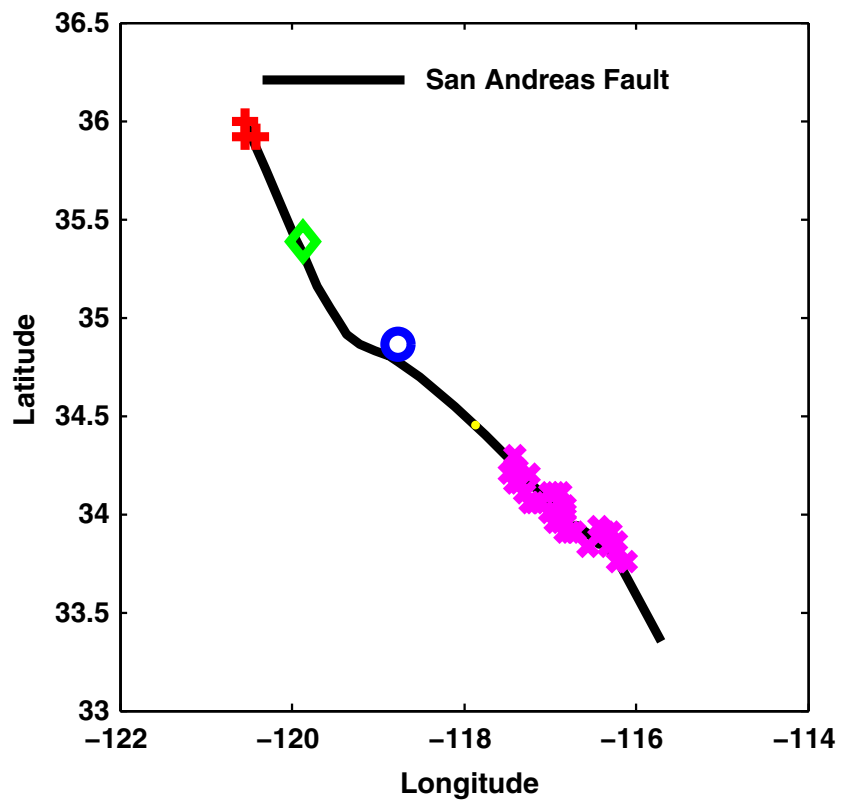

Figure 8. Locations along the southern San Andreas fault at which stress estimates are available from the World Stress Map project. Five data clusters are shown (plus-, diamond-, circle-, dot-, and cross-marked points). The color version of this figure is available only in the electronic edition.

signed for all subevents along depth at that location based on laboratory observations. If $S \leq 1.77$, it is assumed that stress conditions exist for rupture to be able to transition to supershear speeds. The transition length $\left(L_{\mathrm{t}}\right)$ is given by Rosakis et al. (2007) as

$$
\begin{aligned}
& L_{\mathrm{t}}=L_{\mathrm{c}} f(S), \\
& L_{\mathrm{c}}=\frac{G\left(\tau_{p}-\tau_{r}\right) d_{o}}{\pi(1-\nu)\left(\tau-\tau_{r}\right)^{2}} ; f(S)=9.8(1.77-S)^{-3},
\end{aligned}
$$

in which $L_{\mathrm{c}}$ is the critical crack length, $d_{o}$ is the characteristic slip chosen randomly from a uniform distribution between 0.5 and $1 \mathrm{~m}$ (Ide and Takeo, 1997), and $\nu(=0.25)$ is the Poisson's ratio. If $L_{\mathrm{t}}$ is less than the along-length distance from hypocenter to the location under consideration, a local rupture speed of $1.67 V_{S}$ is assigned for all the subfaults along depth at that location on the fault; otherwise, rupture speed is set at $0.87 V_{S}$. Thus, rupture is assumed to propagate at one of two speeds, either a sub-Rayleigh speed of $0.87 V_{S}$ or a supershear speed of $1.67 V_{S}$. Although shear-wave speed may vary locally along the fault, here, we assume a constant $V_{S}$ of $3.29 \mathrm{~km} / \mathrm{s}$, resulting in a bimodal distribution of two rupture speeds, $2.86 \mathrm{~km} / \mathrm{s}$ and $5.49 \mathrm{~km} / \mathrm{s}$. It should be noted that the changing strike on faults such as the San Andreas may affect rupture speeds. Here, we assume that the effect of the changing strike on the principal stress orientations on the fault fully accounts for its effect on rupture speed. We do not explicitly consider fault geometry in the determination of the rupture speed distribution. 


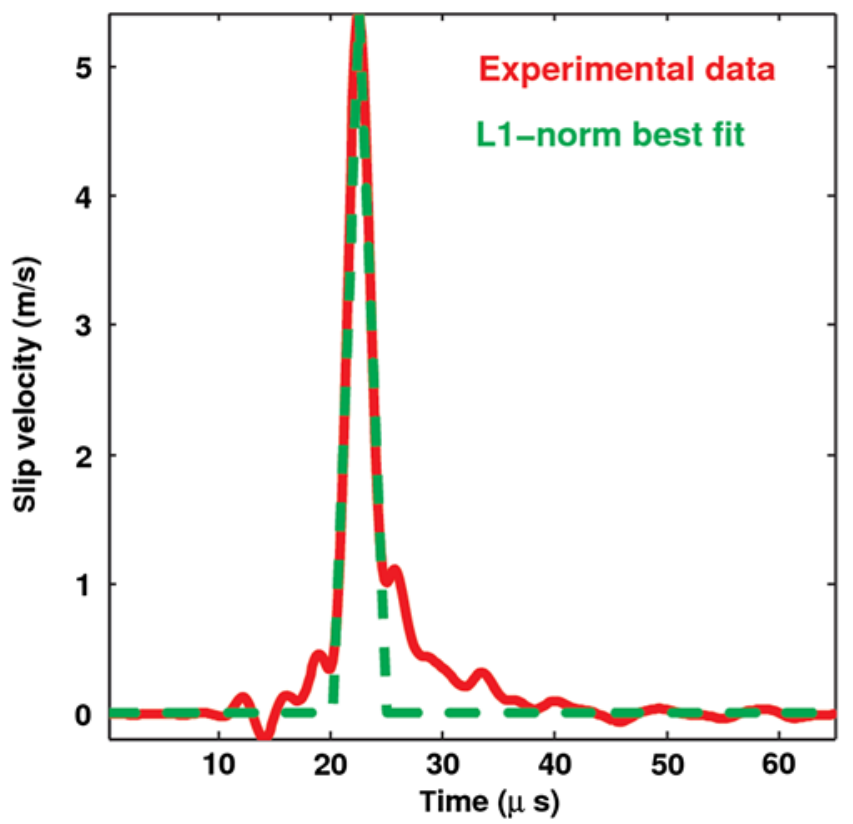

Figure 9. Slip velocity plotted as a function of time for a laboratory earthquake and the best-fitting isosceles triangular slip velocity-time function. The color version of this figure is available only in the electronic edition.

\section{Slip Velocity-Time Function}

We use triangular slip velocity-time functions in our stochastic sources. The parameters are determined using data from a catalog of pulse-like laboratory earthquakes. Using an $L_{1}$ norm, we fit isosceles triangles to the slip velocity-time functions measured in the laboratory (see e.g., Fig. 9). It turns out that the slip-to-rise-time ratios so obtained for all available laboratory earthquakes can be reasonably well characterized by a lognormal distribution (see Fig. 10) with mean 2.605 and standard deviation 1.167 .

For a given slip model, we generate a realization of slip to rise-time ratio using this distribution. Because fault slip is known within each subevent, we can compute the rise time and hence the slip velocity within each subevent. It is possible that the random realization of the slip-to-rise-time ratio can result in extremely large unrealistic rise times. To avoid such anomalous realizations, we once again turn to the finitesource inversions of the 56 earthquakes cataloged in the ETH database (see Data and Resources). The maximum rise time $\left(T_{\mathrm{r}}^{\max }\right)$ as a function of earthquake magnitude for these events is shown in Figure 11. A linear trend is observed, and the best-fitting relation is given by

$$
0.5 T_{\mathrm{r}}^{\max }=1.5 M_{\mathrm{w}}-8.3 .
$$

For a stochastic source of a given magnitude, if the maximum rise time in the model exceeds $T_{\mathrm{r}}^{\max }$ from equation (8), we discard this rise-time distribution and generate a new realization for the slip-to-rise-time ratio.

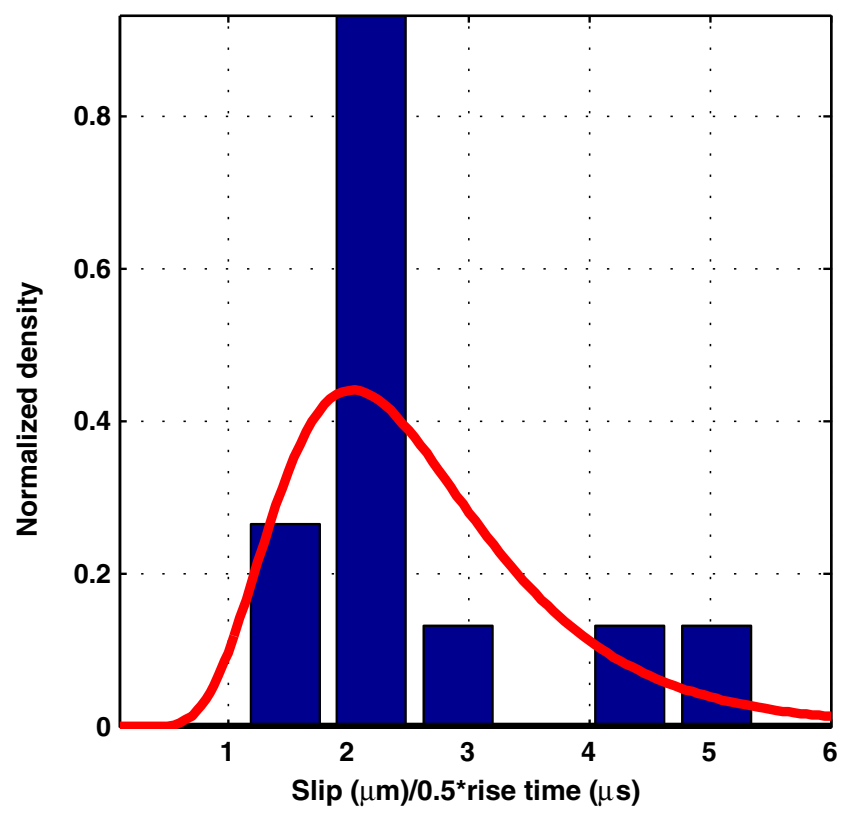

Figure 10. Normalized histograms of slip-to-rise-time ratio observed in laboratory earthquakes and the associated lognormal fit. The color version of this figure is available only in the electronic edition.

\section{Application to the Southern San Andreas Fault}

Using the recursive division algorithm, we generate a suite of five stochastic source-model realizations, each for an $M_{\mathrm{w}} 7.9$ and an $M_{\mathrm{w}} 6.05$ earthquake along the Southern San Andreas fault. Each source realization is placed at five uniformly spaced locations starting at Parkfield in central California and terminating at Bombay Beach in southern California (e.g.s, Figs. 12 and 13). Two rupture directions are considered for each location: north to south and south to north. This leads to 10 rupture scenarios for each of the five source realizations and a total of 50 unilaterally propagating earthquakes (five source realizations $\times$ five rupture locations $\times$ two rupture propagationdirections) for either magnitude level.

In reversing the rupture directions, the slip distributions are also reversed, while maintaining the right-lateral strikeslip nature of the source. The hypocenter is chosen to be at the beginning of each rupture at a depth $d / 2$, in which $d$ is the seismogenic depth. Rupture initiation time at each subfault is computed assuming a circular rupture front. Using SPECFEM3D (Komatitsch and Tromp, 1999; an opensource seismic-wave propagation package based on the spectral element method), three-component waveforms are computed at 636 sites (Fig. 14) in southern California for all 50 scenarios. The waveforms are low-pass filtered with a corner at $2 \mathrm{~s}$ (the underlying Southern California Earthquake Center [SCEC] Community Velocity Model-Harvard [CVM-H] wavespeed model [Plesch et al., 2011] is capable of resolving waves with periods $>2$ s only).

To ensure that the source models generated by the recursive division algorithm are credible, we make qualitative and statistical comparisons of the peak ground velocities (PGVs) 


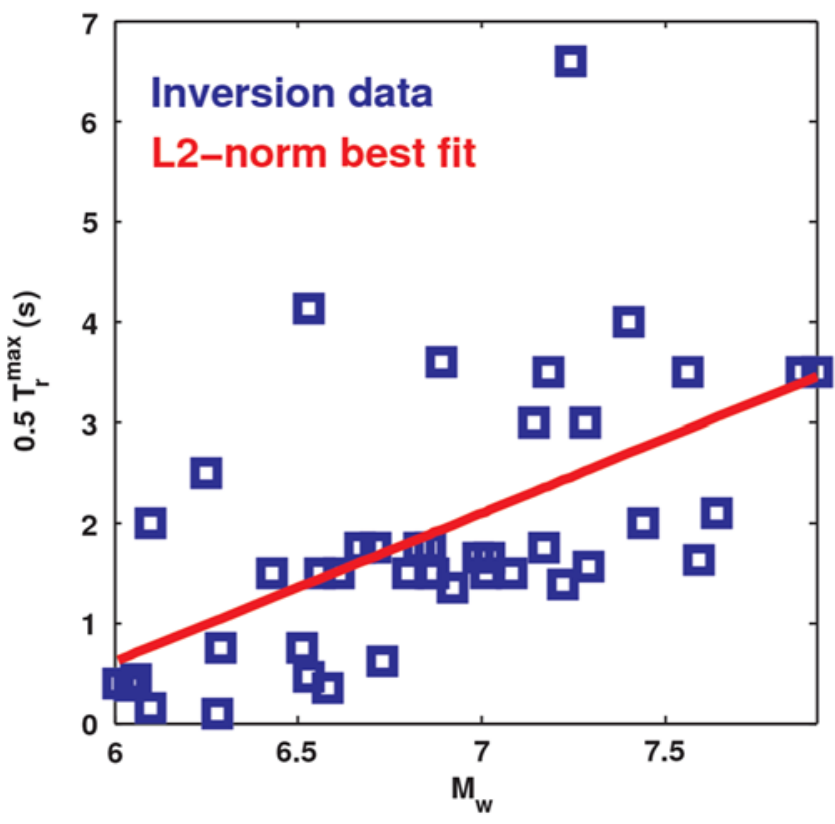

Figure 11. Maximum rise times in finite-source inversions of 56 past earthquakes plotted as a function of their magnitudes. The linear trend is best captured by equation (8) (straight line). The color version of this figure is available only in the electronic edition.

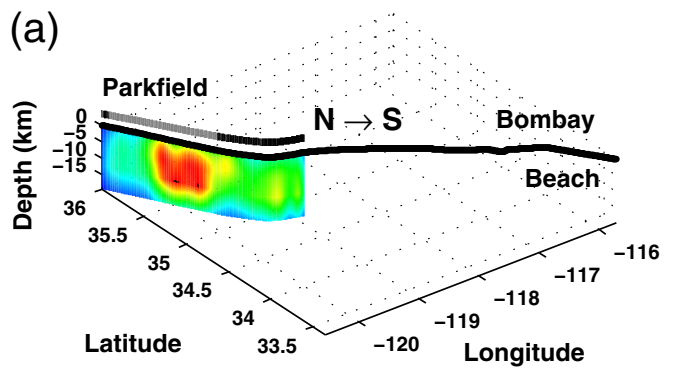

generated by these models against the peak velocities generated by finite-source inversions of comparable earthquakes with similar magnitudes (also simulated using SPECFEM3D). The finite-source inversions selected for this exercise include that of the $2002 M_{\mathrm{w}} 7.9$ Denali fault earthquake (Krishnan et al., 2006; Fig. 15) and the $2004 M_{\mathrm{w}} 6.0$ Parkfield earthquake (Ji, 2004). Whereas the Parkfield earthquake occurred on the San Andreas fault, the last big earthquake (magnitude greater than 7.5) to occur there was the magnitude 7.9 Fort Tejon earthquake in 1857. In the absence of data from a large earthquake on the San Andreas fault, the next best alternative for validation is a big earthquake on a geometrically similar fault, such as the Denali fault in Alaska. Fortunately, the 2002 earthquake was reasonably well recorded and a joint finite-source inversion using teleseismic body and strong-motion waveforms as well as Global Positioning System vectors is available (Krishnan et al., 2006). It has been common practice to simulate ground motions using finite-source inversions, and it would be important to compare and contrast ground motions generated by such sources and the stochastic source models from our algorithm. The results of the validation exercise for the $M_{\mathrm{w}} 7.9$ earthquake are presented here, whereas the results corresponding to the $M_{\mathrm{w}} 6.0$

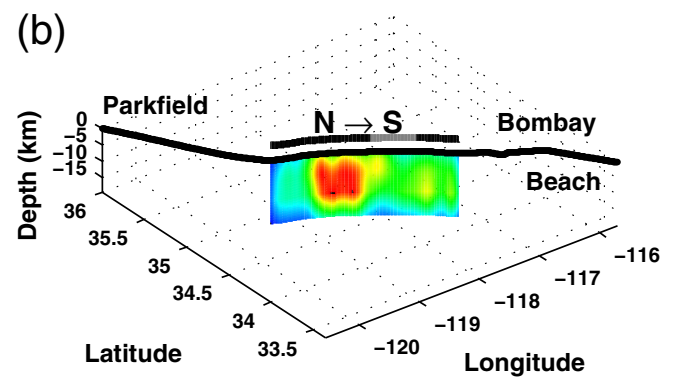

Figure 12. One of five stochastic source realizations (the median model) for the north-to-south rupture of a hypothetical $M_{\mathrm{w}} 7.9$ earthquake on the southern San Andreas fault. Two possible rupture locations, identified as (a) rupture location 1 and (b) rupture location 3, are shown. The rupture speed distribution is also shown on top of the slip. The gray line segments indicate rupture propagating at the subRayleigh speed of $0.87 V_{S}$, whereas the black lines indicate rupture propagating at the supershear speed of $1.67 V_{S}$. Rupture speed is held constant along fault depth. The model has a constant slip velocity of $4.15 \mathrm{~m} / \mathrm{s}$. The color version of this figure is available only in the electronic edition.

(a)

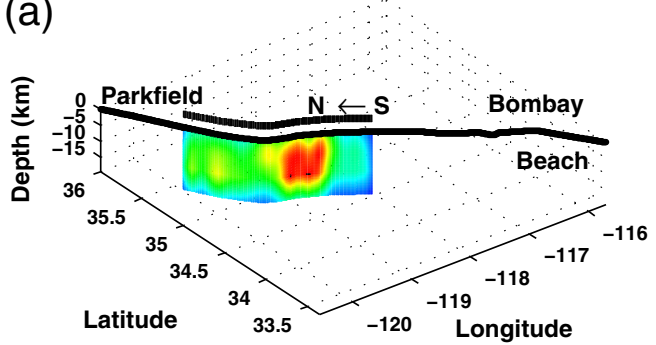

(b)

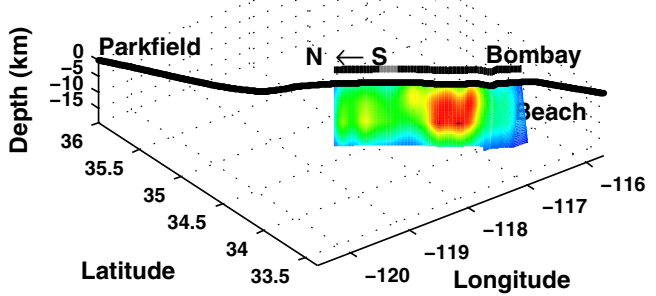

Figure 13. One of five stochastic source realizations (the median model) for the south-to-north rupture of a hypothetical $M_{\mathrm{w}} 7.9$ earthquake on the southern San Andreas fault. Two possible rupture locations, identified as (a) rupture location 2 and (b) rupture location 4, are shown. The rupture speed distribution is also shown on top of the slip. The gray line segments indicate rupture propagating at the subRayleigh speed of $0.87 V_{S}$, whereas black lines indicate rupture propagating at the supershear speed of $1.67 V_{S}$. Rupture speed is held constant along fault depth. The model has a constant slip velocity of $4.15 \mathrm{~m} / \mathrm{s}$. The color version of this figure is available only in the electronic edition. 


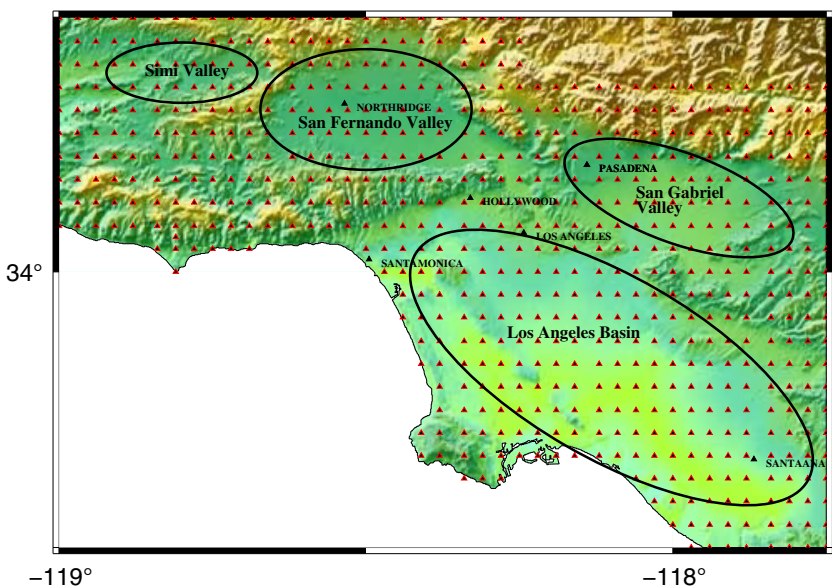

Figure 14. The geographical distribution of the 636 southern California sites (triangles) where ground motions are computed. The spacing between the sites is $\sim 3.5 \mathrm{~km}$. The ellipses identify the basins in southern California: Simi Valley, San Fernando Valley, San Gabriel Valley, and the Los Angeles basin. The color version of this figure is available only in the electronic edition.

earthquake are available in the (E) electronic supplement to this article. We select the median source model from the stochastic model set for the validation exercise, considering that most engineering applications are concerned with median ( \pm 1 standard deviation) ground motions rather than extreme ground motions. However, it should be pointed out that in the absence of greater data from large earthquakes such as the Denali, it is hard to judge whether the ground motions from the Denali event are typical of such events or whether they are on the high or low side. This, unfortunately, is the best we can do presently as far as validation is concerned. The method for selecting the median source is as follows:

1. For each of the five stochastic source realizations, we compute the median PGV for the two horizontal components of the synthetic ground-motion waveforms at 636 sites from each of the 10 rupture scenarios (five rupture locations $\times$ two rupture directions).

2. For each of the five stochastic source realizations, we compute the median value of the 10 median PGVs for the 10 rupture scenarios from (1), separately for the two horizontal components. The solid lines in Figure 16 illustrate this median PGV for each of the five stochastic source realizations for the hypothetical $M_{\mathrm{w}}$ 7.9 San Andreas fault earthquake.

3. To identify the median source model, we compute the median PGV of the ground motions produced at the 636 sites by all 50 scenario earthquakes. The dashed lines in Figure 16 correspond to this median value of PGV for the north-south and east-west ground-motion components for the hypothetical $M_{\mathrm{w}}$ 7.9 San Andreas fault earthquake.

4. Of the five stochastic source realizations, the source for which median PGV (square root sum of squares of eastwest and north-south PGVs) is closest to the corresponding median PGV produced by all five source realizations (computed in [3]) is taken to be the median model and the ground motions produced by this model are used in the validation exercise. The rupture speed within the median model varies depending upon the location of rupture, whereas the distribution of slip and rise time remain unchanged.

To study qualitative differences between the ground motion generated by the stochastic median model and the Denali finite-source inversion model, we map these models onto the San Andreas fault at rupture location 3, approximately midway between Parkfield and Bombay Beach (Fig. 17), and directly due north of the Los Angeles basin. Both north-tosouth and south-to north rupture propagation directions are simulated. The location of the largest asperity in the stochastic mean model is offset from that of the Denali model by about $100 \mathrm{~km}$. This has a significant influence on the nature of the resulting ground motion. It should be noted that even

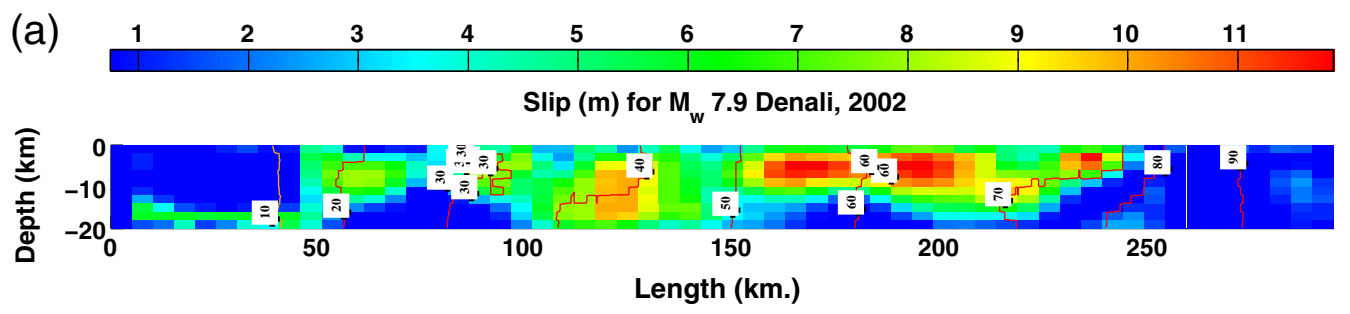

(b)

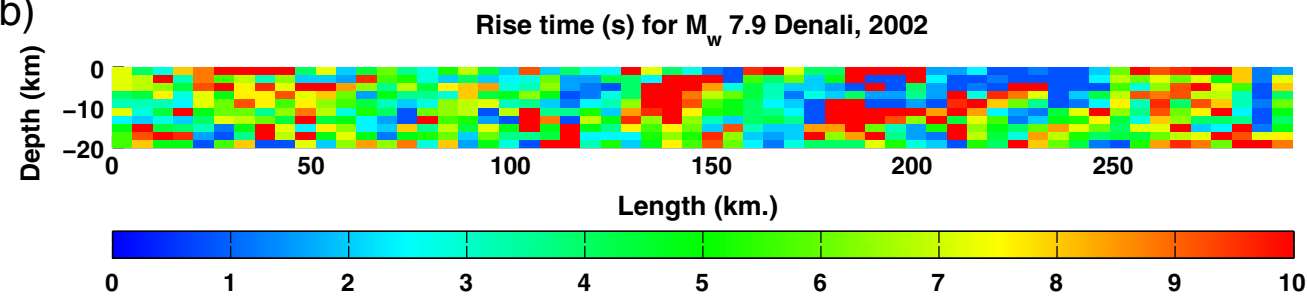

Figure 15. (a) Slip (m) and (b) rise-time (s) distributions from a finite-source inversion of teleseismic, strong motion, and Global Positioning System data from the $M_{\mathrm{w}} 7.9$ Denali fault earthquake of 2002 (Krishnan et al., 2006). Rupture time (s) contours are overlaid on the slip distribution. The color version of this figure is available only in the electronic edition. 


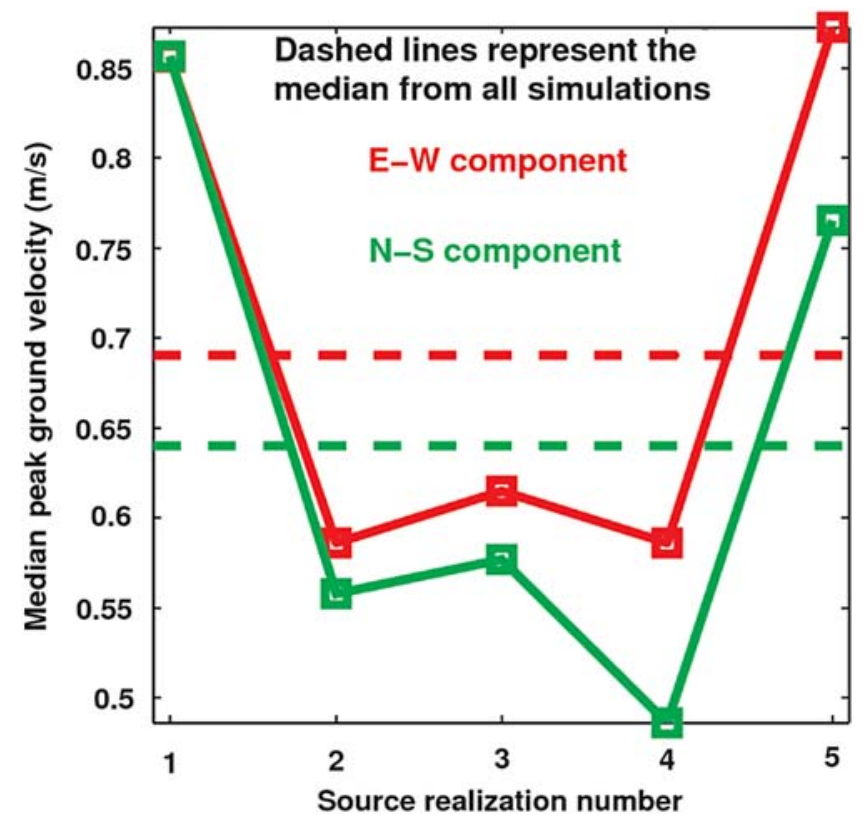

Figure 16. The solid lines are median peak ground velocity (PGV) computed at 636 sites in southern California from 10 rupture scenarios (five rupture locations along the southern San Andreas fault $x$ two rupture directions) using each of five stochastic source realizations. The dashed lines are the corresponding median PGV from all 50 scenario earthquakes. All earthquakes are of magnitude $M_{\mathrm{w}}$ 7.9. (E-W, east-west component; N-S, north-south component.) The color version of this figure is available only in the electronic edition.

though the length of the Denali source is longer ( $290 \mathrm{~km})$ than the stochastic source $(\sim 210 \mathrm{~km})$, there is a large concentration of subfaults with zero slip toward the end of the rupture (see Figs. $5 \mathrm{f}$ and 15). Slip is predominantly concentrated within a length of $200 \mathrm{~km}$ (between 50 and $250 \mathrm{~km}$ ).

The PGV of the east-west and north-south components of ground motion simulated using the stochastic median model is shown in Figure 18a,b. Figure 18c,d shows similar maps generated using the Denali source model. The corre- sponding peak ground displacement (PGD) maps are given in Figure 19. The peak motions produced by the stochastic median model are far more intense in the Los Angeles basin than in the San Gabriel Valley, which is located east of the Los Angeles basin. The reverse is true for the motions generated by the Denali source model. This is directly attributable to the location of the largest asperity in the two models. In the north-to-south rupture, the largest slip asperity in the stochastic median model occurs to the west of the midpoint of the source, whereas the same occurs to the east of the midpoint in the Denali source. Thus, ground motions from the Denali model are stronger in the east, whereas ground motions from the stochastic model are stronger in the midsection of the greater Los Angeles region. The PGD maps are strongly correlated with the PGV maps in both cases.

In the case of a rupture propagating south to north, the large asperity in the Denali model is further northwest compared with the asperity in the stochastic median model. As a result, ground motions from the Denali model are more intense in the Los Angeles basin and less intense in the San Gabriel Valley, whereas the reverse is true for the ground motions from the stochastic median model (Fig. 20).

In general, peak ground-motion distribution from the stochastic median and Denali source models located at various sections along the southern San Andreas fault seems to be dictated strongly by the relative location of the slip asperities. For north-to-south propagating ruptures, the location of intense ground motions moves gradually from Simi Valley to San Fernando Valley, on to Los Angeles basin, and finally to San Gabriel Valley as the hypocenter location is progressively changed from Parkfield toward Bombay Beach. Intense ground motions from the Denali model occur further southeast compared with that from the stochastic median model, consistent with the fact that the largest slip asperity in the former model is further southeast. These observations are reversed for south-to-north propagating ruptures; that is, the location of intense ground motion moves gradually from (a)

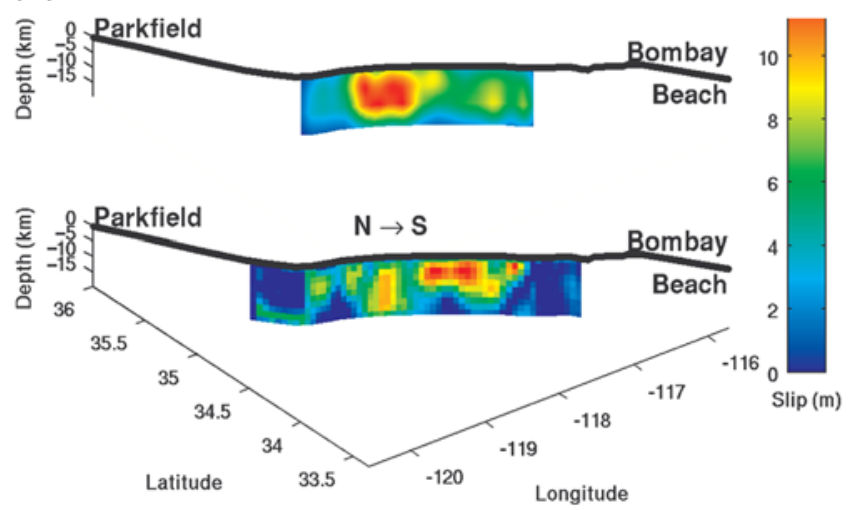

(b)

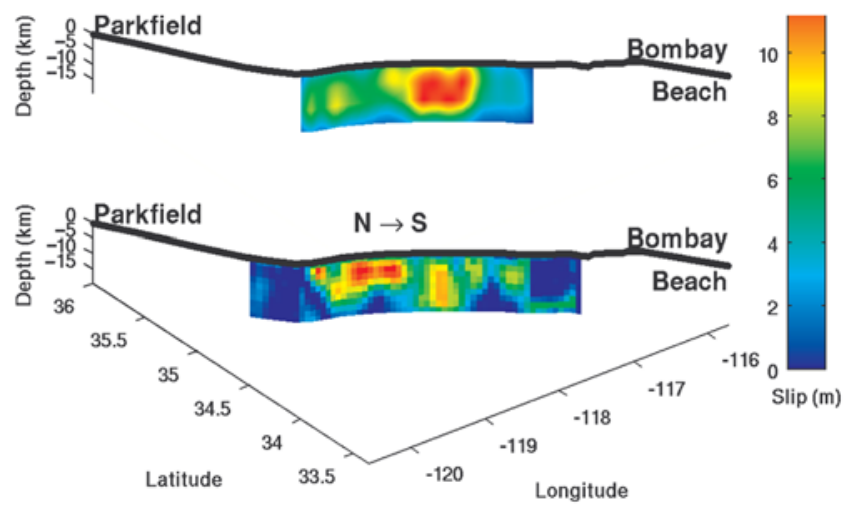

Figure 17. Comparison of (top) the median stochastic source model located at rupture location 3 and (bottom) the Denali fault earthquake finite-source model, also located at rupture location 3. Both (a) north-to-south and (b) south-to-north propagating ruptures are shown. The differences in the slip asperity locations are shown in the two models. The color version of this figure is available only in the electronic edition. 
(a)

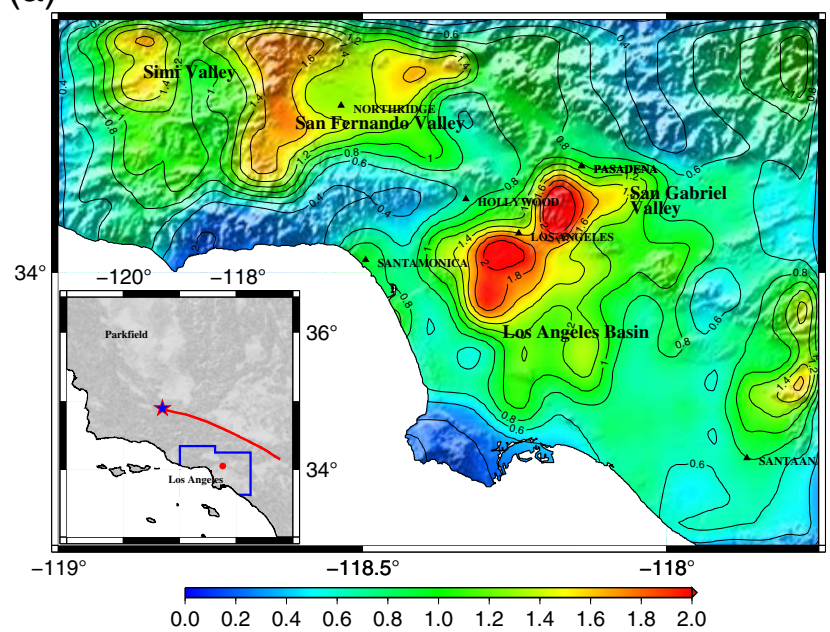

(c)

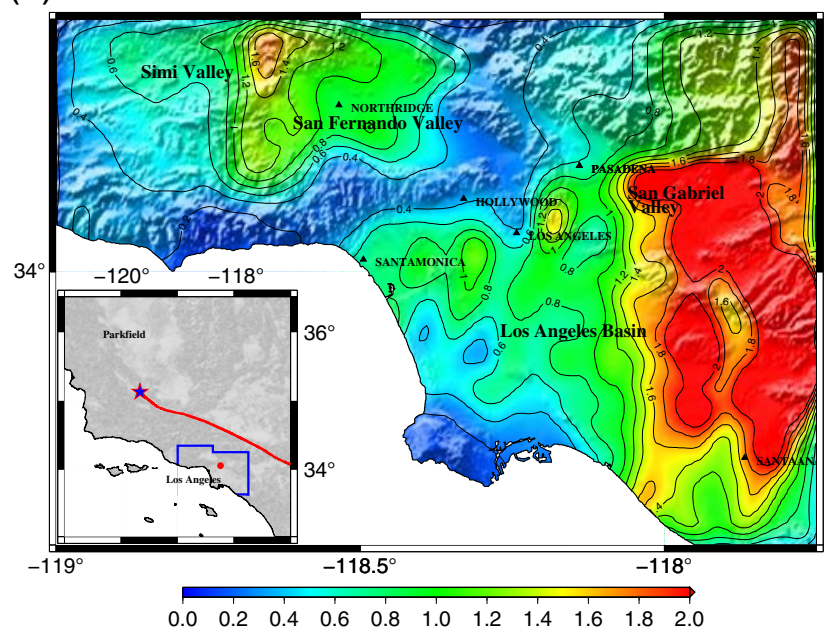

(b)

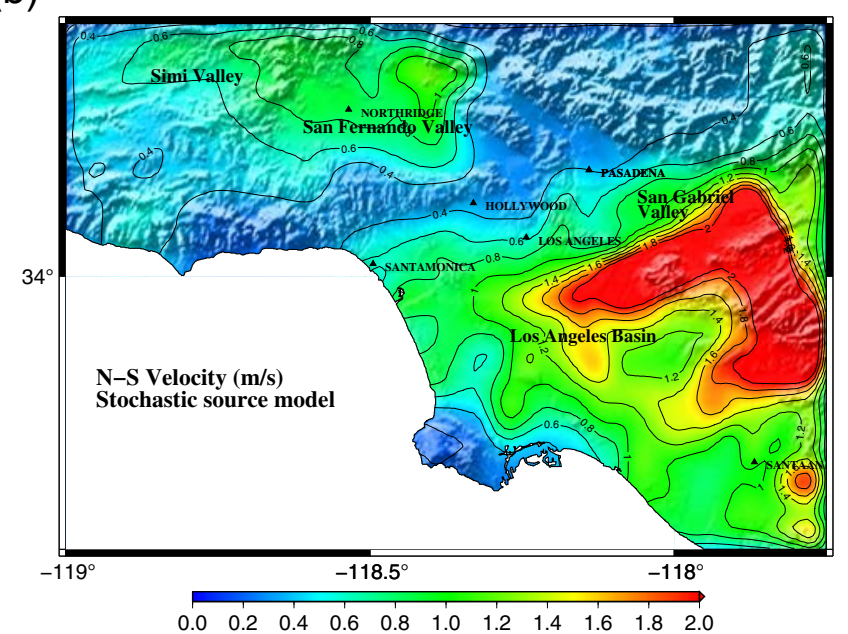

(d)

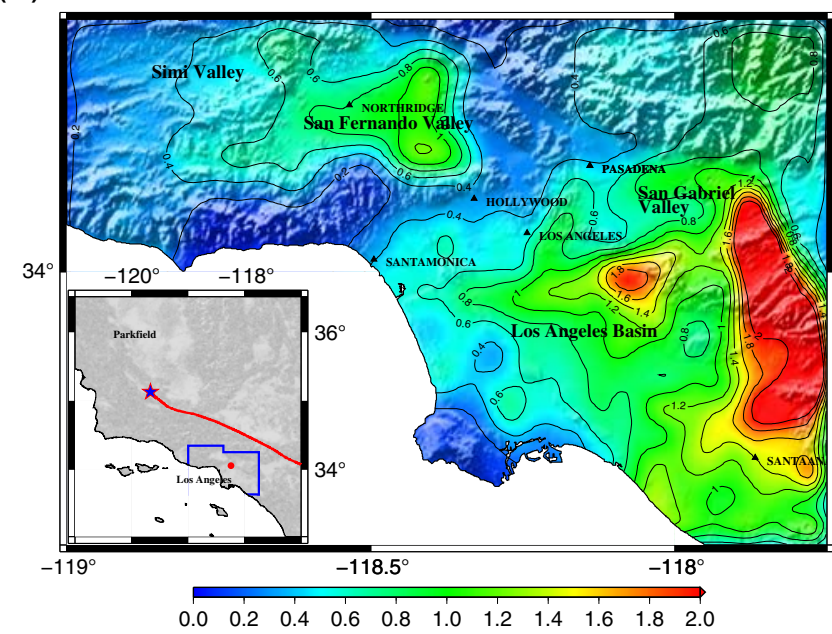

Figure 18. East-west and north-south components of PGV $(\mathrm{m} / \mathrm{s})$ from a north-to-south propagating $M_{\mathrm{w}} 7.9$ rupture at location 3 on the southern San Andreas fault: (a) and (b) the stochastic median source model, and (c) and (d) the Denali earthquake finite-source inversion model (Krishnan et al., 2006). The insets show the fault trace and the hypocenter location. The color version of this figure is available only in the electronic edition.

the San Gabriel Valley to the Los Angeles basin, on to the San Fernando Valley, and finally to the Simi Valley; and strong ground motion from the Denali model occurs further northwest when compared with that generated by the stochastic median model.

In addition to asperity location, another factor leading to differences in the ground motions from the Denali source model and the stochastic median source model is the assumed correlation between rise time and slip in the stochastic model and the lack of the same in the Denali model, even though the maximum rise time for both models is $\sim 6 \mathrm{~s}$. The effect of this correlation can be estimated by comparing the ground motions from the Denali model against that from a modified Denali model. In this modified model, the rise times from the original Denali model are made proportional to the slip using the stochastic source-generation algorithm. All other parameters remain the same as in the original model. Figure 21a and 21b shows the difference in the PGV (east-west component) generated by these two source models (PGV [modified Denali]-PGV [Denali]) for north-to-south ruptures at rupture locations 1 and 3, respectively. Although the differences are not significant in most of the region, clearly there are a few locations where significant differences are seen.

Despite the differences in the modeling of source parameters, the overall intensities of ground motion from the stochastic median model are not vastly different from that produced by the Denali finite-source inversion model. This can be seen in the statistical comparisons shown in Figures 22 and 23. Figure 22 includes the histograms (and PDFs) of PGV for each of the five north-to-south rupture scenarios (at locations 1 through 5). The histograms and the best-fitting lognormal PDFs for the PGVs from the stochastic median model are quite similar to those for the PGVs from the Denali finite-source inversion model. Figure 23 includes the same types of data but for the five south-to-north rupture scenarios. Once again, there is reasonably good agreement between the two, lending 
(a)

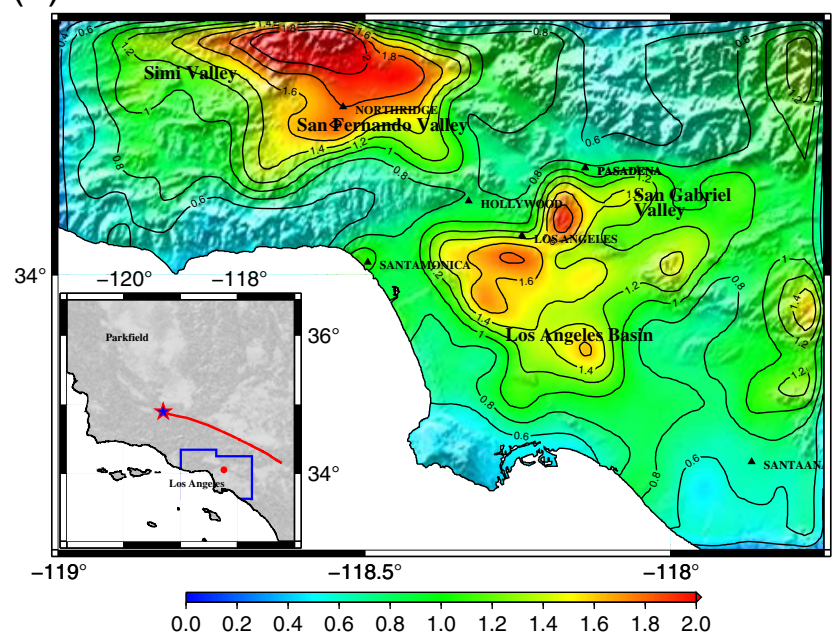

(c)

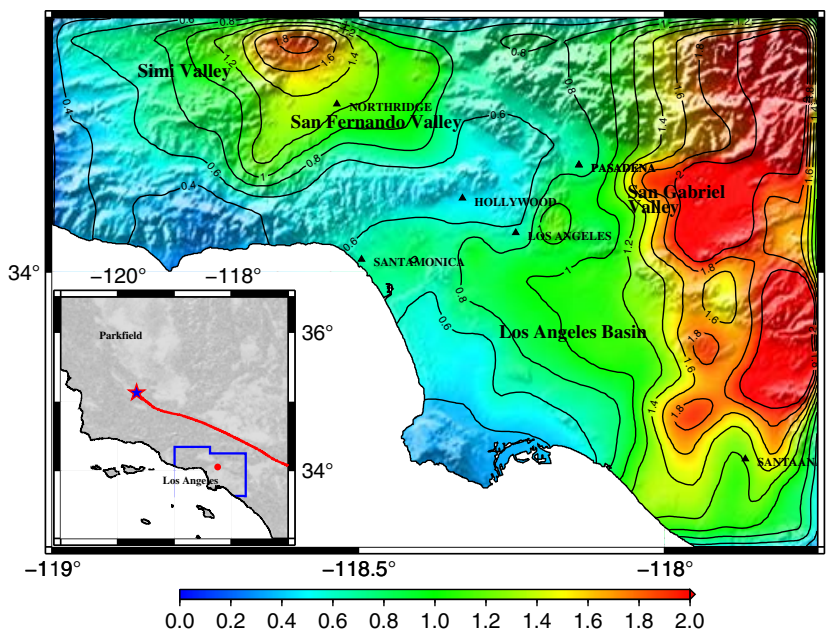

(b)

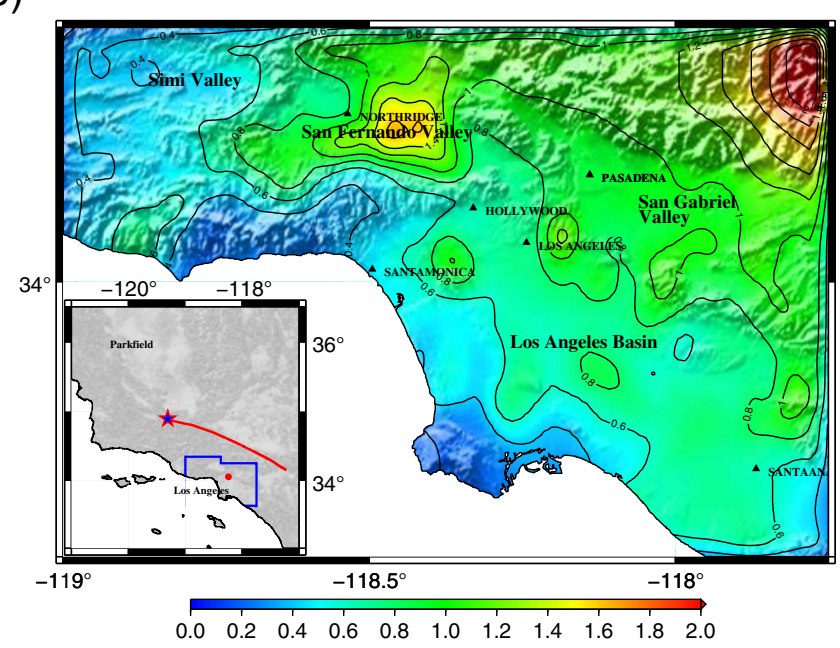

(d)

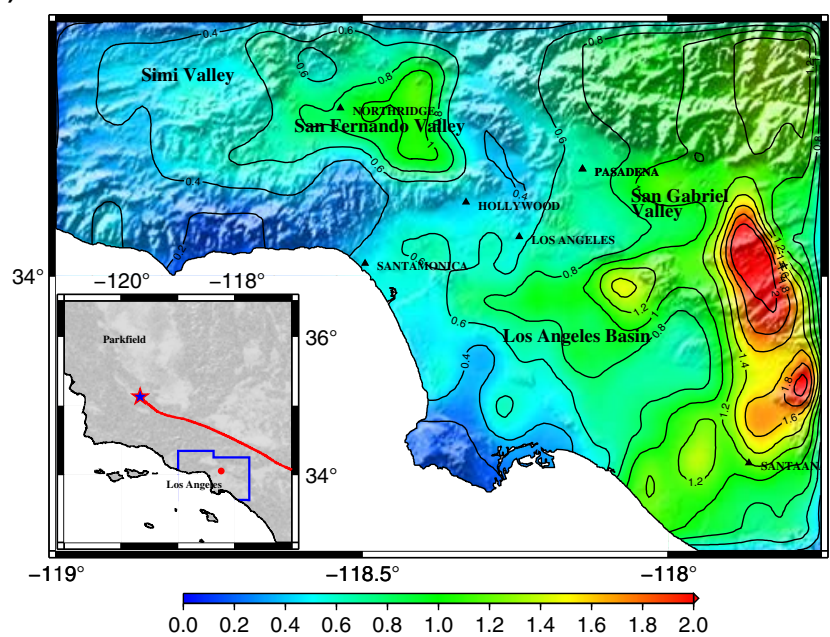

Figure 19. East-west and north-south components of peak ground displacement (PGD) (m) from a north-to-south propagating $M_{\mathrm{w}} 7.9$ rupture at location 3 on the southern San Andreas fault: (a) and (b) the stochastic median source model, and (c) and (d) the Denali earthquake finite-source inversion model (Krishnan et al., 2006). The insets show the fault trace and hypocenter location. The color version of this figure is available only in the electronic edition.

credibility to the source-generation algorithm. It is interesting to note that the south-to-north ruptures produce less-intense ground motions for all rupture scenarios using the Denali source and the stochastic median model alike when compared with the north-to-south ruptures. The comparison of attenuation of ground motion (median peak average horizontal velocity) with distance from source is shown in Figure 24. Once again the agreement between the attenuation of ground motion produced by the stochastic source and the Denali finite-source inversion models is quite good. The median values are computed by collating data in 2-km-wide bins. Source-to-site distance is taken to be the shortest distance from the site to any point on the rupture extent. The lack of data beyond $100 \mathrm{~km}$ in the case of the Denali source is because the Denali source is about $80 \mathrm{~km}$ longer than the stochastic sources.

Ground-motion prediction equations (GMPEs), developed on the basis of data collected from global earthquakes, have been used extensively in engineering applications, including the design of buildings. It would be useful to understand how the ground motions generated by the median stochastic source model compare against the median motions predicted by GMPEs. Olsen and Mayhew (2010) have outlined a wide array of goodness-of-fit metrics for use in broadband ground-motion simulation validation (Baker et al., 2014). Of these, $\mathrm{PGV}, \mathrm{PGD}$, and spectral acceleration at $3 \mathrm{~s}\left(\mathrm{SA}^{3 s}\right)$ are the most relevant metrics for the comparison of long-period motions, the primary focus of this study. Figure 25 shows the median peak horizontal velocity and displacement (and median \pm 1 standard deviation) as a function of distance from source simulated at sites in the greater Los Angeles region that are within $100 \mathrm{~km}$ of the median stochastic source model $\left(M_{\mathrm{w}} 7.9\right)$ for the 10 rupture scenarios described previously (rupture locations 1-5, and rupture directions north-to-south and south-to-north). The median values are computed by 
(a)

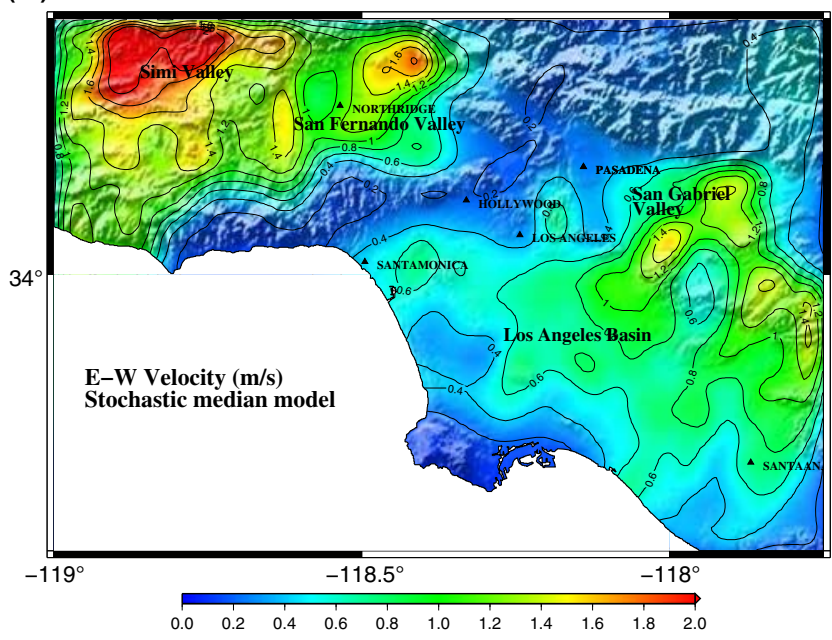

(b)

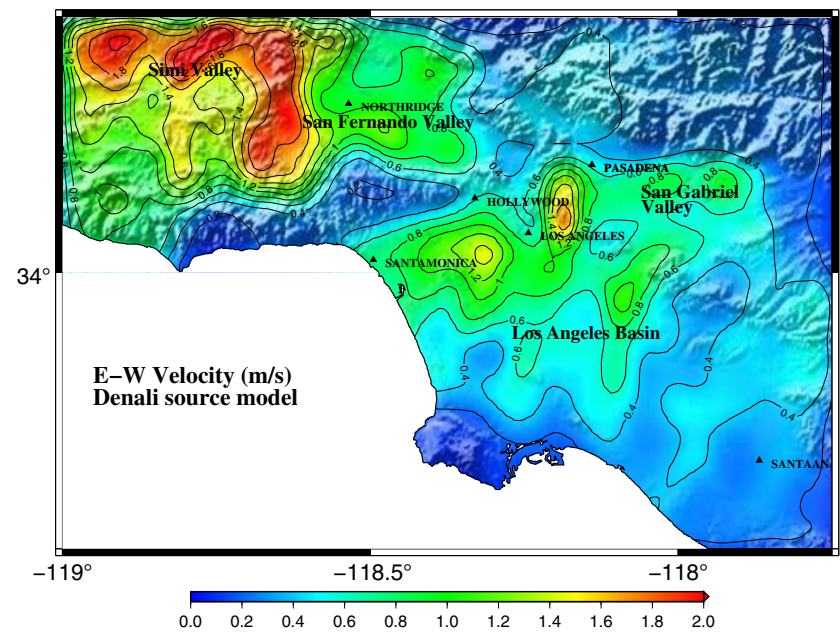

Figure 20. East-west component of PGV (m/s) from a south-to-north propagating $M_{\mathrm{w}} 7.9$ rupture at location 3 on the southern San Andreas fault: (a) the stochastic median source model, and (b) the Denali earthquake finite-source inversion model (Krishnan et al., 2006). The color version of this figure is available only in the electronic edition.

(a)

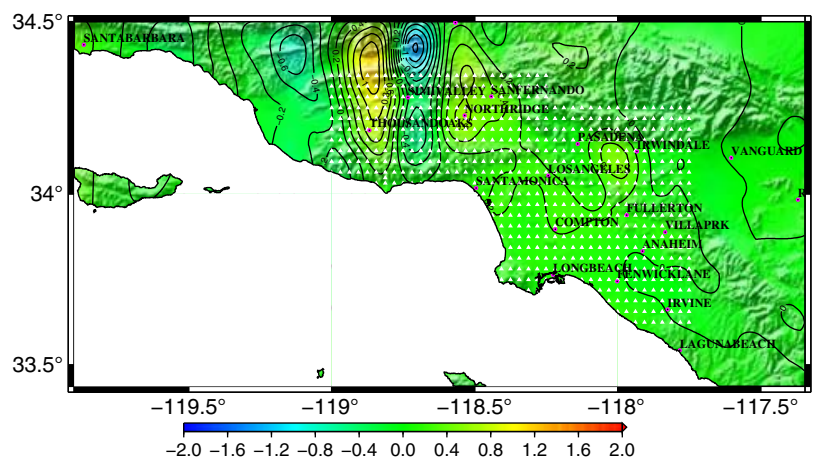

(b)

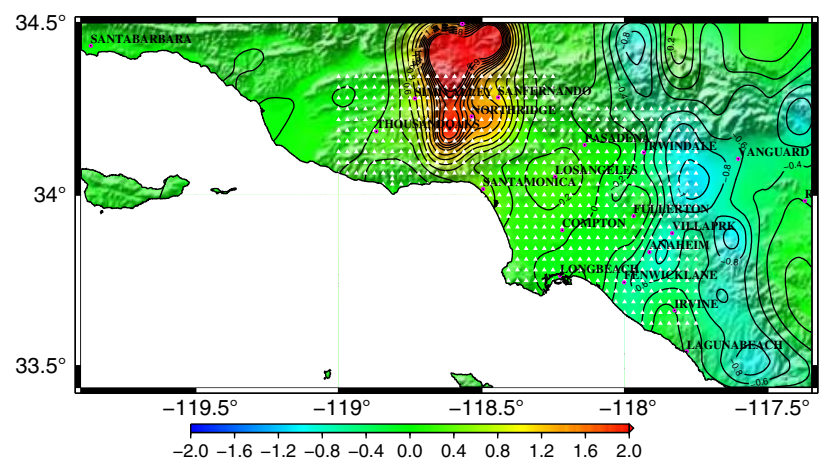

Figure 21. (a) and (b) Difference in the PGV (east-west component) generated by the Denali source model and the modified Denali model (PGV [modified Denali]-PGV [Denali]) for north-to-south ruptures at rupture locations 1 and 3, respectively. The modified Denali model is obtained by making the rise times from the original Denali model proportional to the slip using the stochastic source-generation algorithm. The color version of this figure is available only in the electronic edition.

collating data in 2-km-wide bins. The corresponding groundmotion prediction by the Campbell-Bozorgnia Next Generation Attenuation (NGA) relation is also shown for comparison (Campbell and Bozorgnia, 2008). The average shear-wave velocity between 0 and $30 \mathrm{~m}$ depth $\left(V_{S 30}\right)$ and basin depth for these stations (Fig. 26) are taken from Wald and Allen (2007) and the SCEC CVM-H (Plesch et al., 2011), respectively. In addition to the source and path effects, the other important factors that dictate ground-motion intensities are the basin depth and shear-wave velocities in the topsoil or geotechnical layer $\left(V_{S 30}\right)$. In general, greater basin depths and/or lower $V_{S 30}$ values lead to stronger ground motion. For the five rupture locations considered here, basin sites are located at distances no smaller than $40 \mathrm{~km}$. This leads to significant amplification in the simulations at distances $>40 \mathrm{~km}$. The NGA relations also show the amplification due to the presence of basins. The peak displacements in the basins predicted by the simulations match quite well with the GMPE predictions. However, the same cannot be said of the PGVs or spectral accelerations at $3 \mathrm{~s}$ (Fig. 27). Median PGVs in the basins from the simulations are three to six times that predicted by the Campbell-Bozorgnia NGA relation. The same holds true for $\mathrm{SA}^{3 s}$ as well. It is possible that the bimodal rupture speed in our source model combined with the coherence in the source parameters (constant slip rate) may be causing stronger directivity effects. However, the good agreement in the NGA and simulation predictions for PGD seems to indicate otherwise.

There has been a concerted effort at the SCEC toward the simulation of broadband ground motion. Recent largescenario earthquake simulations on the southern San Andreas fault include Terashake (e.g., Olsen et al., 2008; Ely et al., 2010), ShakeOut (e.g., Bielak et al., 2010; Graves 
(a)

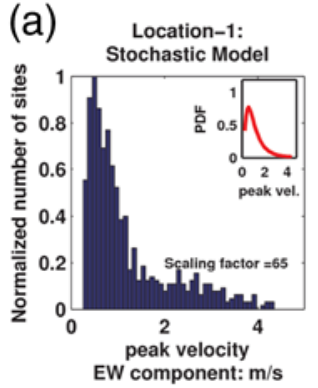

(f) Location-1:

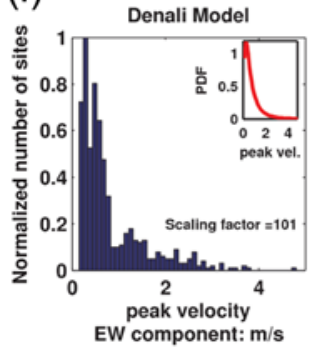

(b)

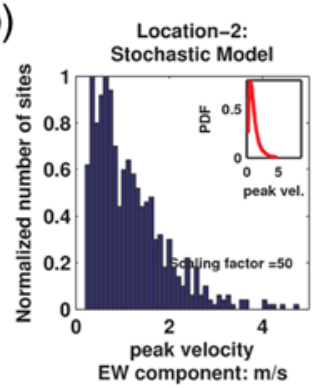

(g)

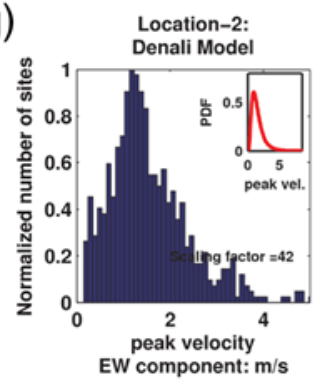

(c)

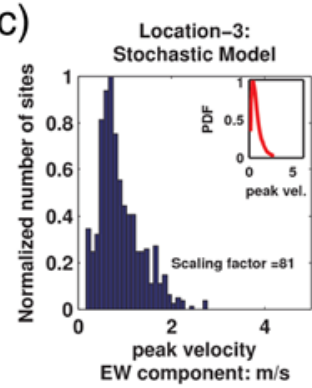

(h)

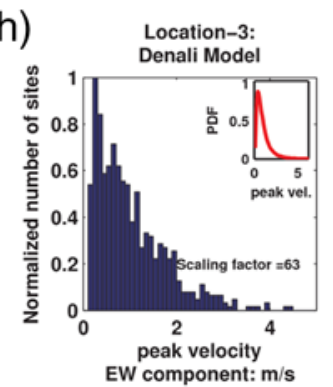

(d)

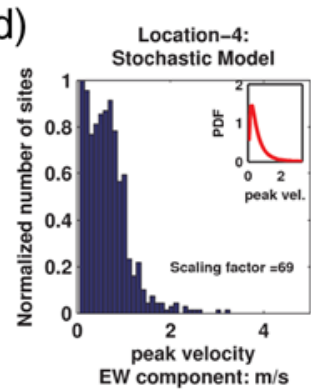

(i)

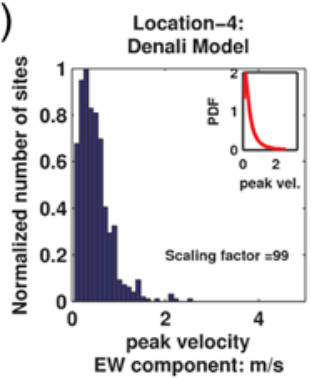

(e)

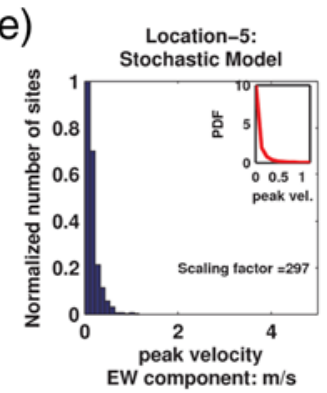

(j)

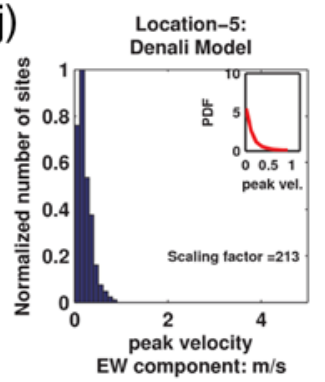

Figure 22. Five $M_{\mathrm{w}} 7.9$ north-to-south rupture scenarios (at locations 1-5) on the San Andreas fault using (a)-(e) the stochastic median model and (f)-(j) the Denali finite-source inversion model: histograms and best-fit lognormal PDFs (insets) of PGV at 636 sites in southern California. The product of the listed scaling factor and the normalized histogram ordinate at a specific peak velocity gives the total number of sites for that velocity. The color version of this figure is available only in the electronic edition.
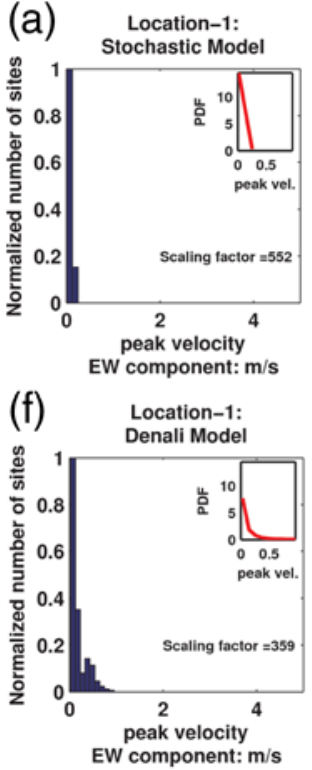

(b)

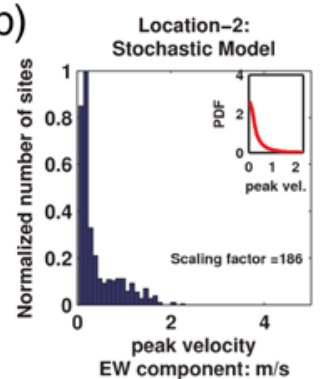

(g)

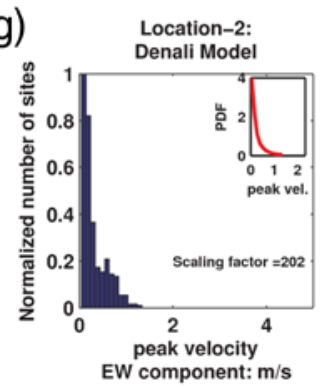

(c)

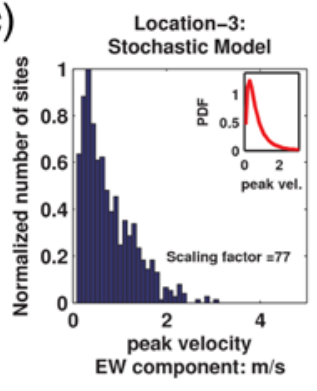

(h)

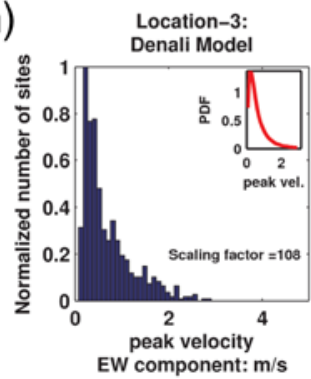

(d)

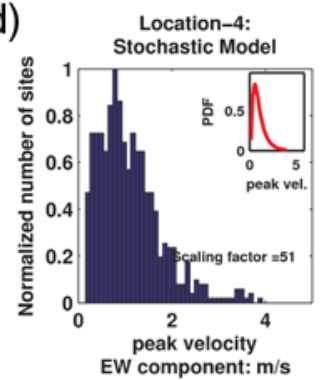

(i)

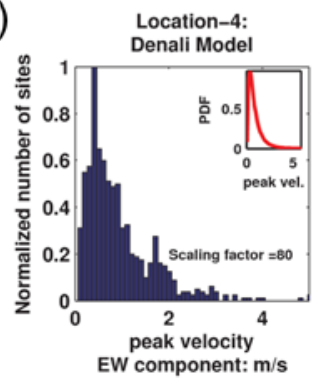

(e)

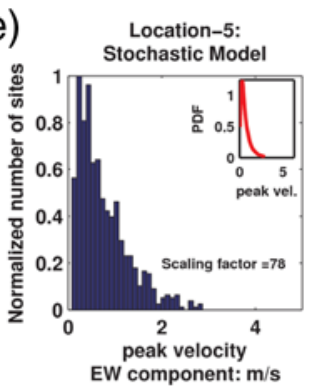

(j)

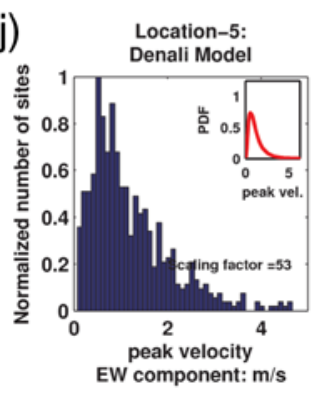

Figure 23. Five $M_{\mathrm{w}} 7.9$ south-to-north rupture scenarios (at locations 1-5) on the San Andreas fault using (a)-(e) the stochastic median model and (f)-(j) the Denali finite-source inversion model: histograms and best-fit lognormal PDFs (insets) of PGV at 636 sites in southern California. The product of the listed scaling factor and the normalized histogram ordinate at a specific peak velocity gives the total number of sites for that velocity. The color version of this figure is available only in the electronic edition.

et al., 2011), and M 8 (e.g., Cui et al., 2010). All these simulations were carried out using the SCEC CVM (Kohler et al., 2003) seismic-wavespeed model, whereas the simulations in this study were carried out using the SCEC CVM-H model, so it may not be possible to make a secular comparison. It is nonetheless useful to understand the variability in the ground motions resulting from the combined effect of different source models and wavespeed models. Here, we compare the $M_{\mathrm{w}} 7.8$ ShakeOut scenario earthquake ground motions against the ground motions produced by the median stochastic source model, described earlier in the section, with epicenter at Bombay Beach and propagating north. The ShakeOut earthquake slip model is shown in Figure 28 . The peak slip $(\sim 15 \mathrm{~m})$ and the peak slip rate $(\sim 4.8 \mathrm{~m} / \mathrm{s})$ are similar to those of the median 


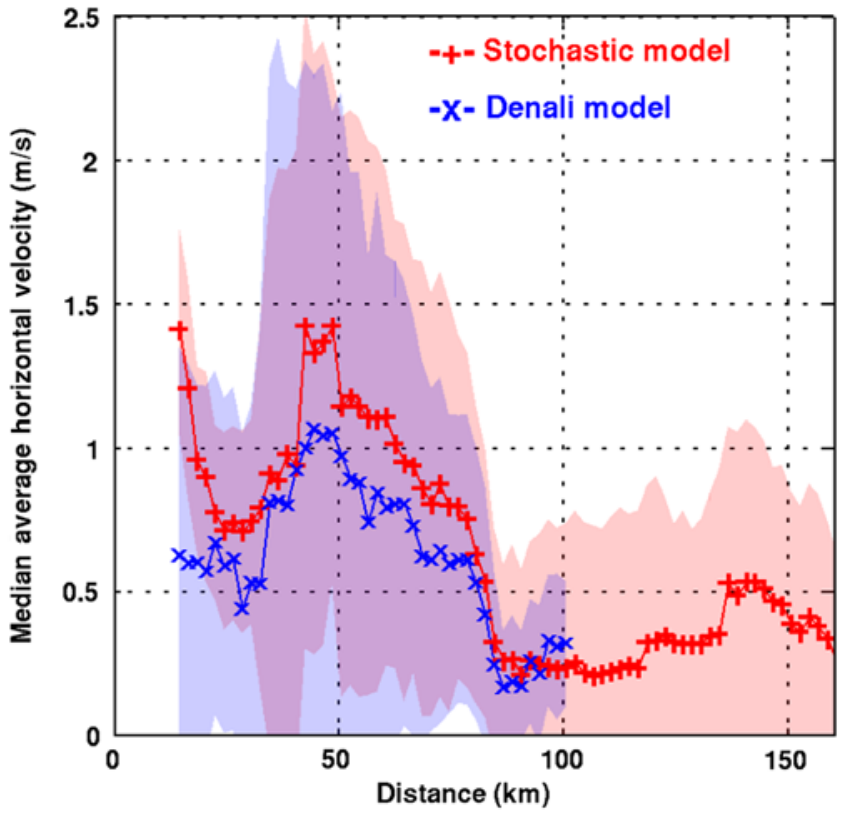

Figure 24. Median peak average horizontal velocity $(\mathrm{m} / \mathrm{s})(+$, stochastic model; $\mathrm{x}$, the Denali model) as a function of source-tosite distance, in southern California due to an $M_{\mathrm{w}} 7.9$ earthquake occuring along the southern San Andreas fault. The shaded region corresponds to median \pm 1 standard deviation. A total of 10 rupture scenarios (five rupture locations $\times$ two propagation directivity) are considered.) The color version of this figure is available only in the electronic edition.

source model ( $11.9 \mathrm{~m}$ and $4.15 \mathrm{~m} / \mathrm{s}$, respectively). The two horizontal components of the PGV from the two source models are shown in Figure 29. The ranges of PGVs observed in the greater Los Angeles region from the two sources are quite similar. The differences in the extent and location of hotspots can be attributed to the differences in the underlying wavespeed models used for the two simulations, the location, size, and intensity of the primary slip asperity and to the differences in the rupture speed distribution. The stochastic source has a bimodal rupture speed distribution $\left(0.87 V_{S}\right.$ or $1.67 V_{S}$ ), whereas the ShakeOut source has a peak rupture speed of $1.4 V_{S}$ at the location of maximum slip, a rupture speed of $0.85 V_{S}$ at locations of average slip, and a rupture speed of $0.2 V_{S}$ at locations with zero slip.

\section{Sensitivity of Ground Motions in the Los Angeles Basin to Source Parameters of Large Ruptures on the San Andreas Fault}

To understand the sensitivity of ground motions in the Los Angeles basin to the source parameters of large ruptures on the San Andreas fault, the recursive division algorithm is applied to generate 50 stochastic seismic source models of an $M_{\mathrm{w}} 7.9$ earthquake. All ruptures are assumed to initiate at Parkfield and propagate south toward Wrightwood, similar to the Fort Tejon earthquake of 1857, the last big earthquake on the southern San Andreas fault. Source parameters of interest include the percentage of asperity area relative to the fault area (an asperity in our model is defined as a minimum of two continuous subfaults where the magnitude of slip in each subfault is greater than or equal to the mean slip), maximum rise time in the source model, and the percentage of the rupture propagating at sub-Rayleigh speeds (alternately percentage of the rupture propagating at supershear speeds). For each scenario earthquake, the peak horizontal ground velocity is calculated at each of the 211 sites in the Los Angeles basin (Fig. 14) as the maximum of the square root of the sum of the squares of the north-south and east-west ground (a)

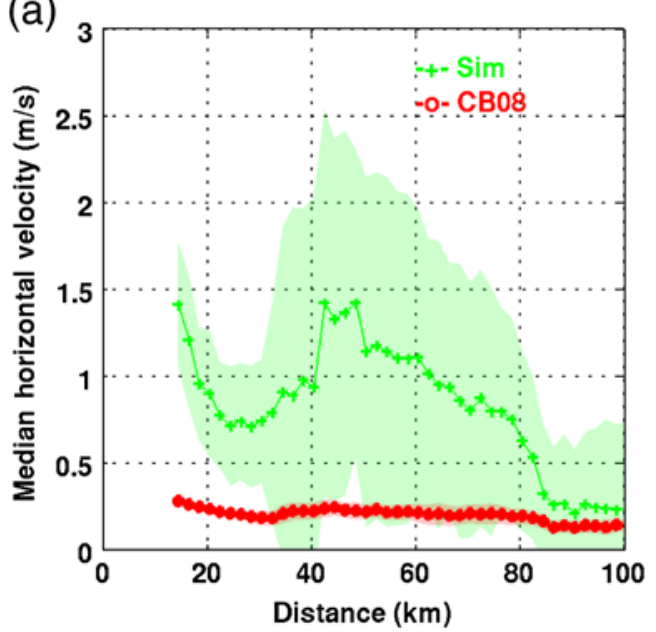

(b)

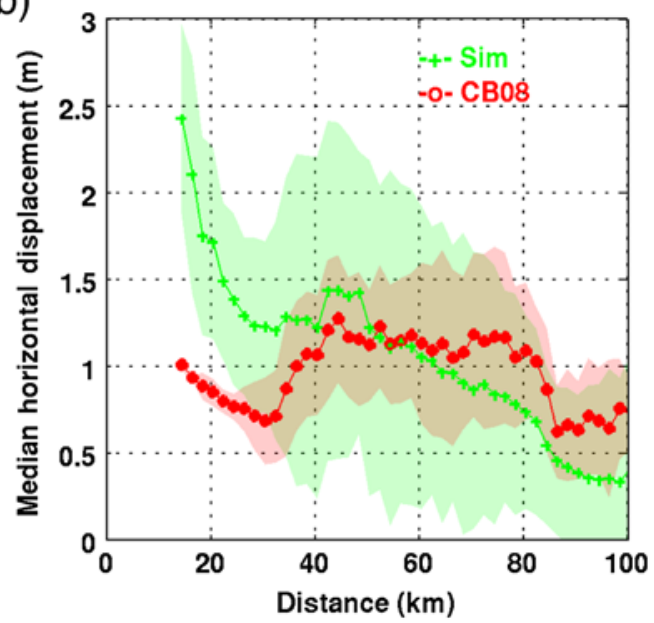

Figure 25. (a) Median peak horizontal velocity (m/s) and (b) median peak horizontal displacement (m) as a function of source-to-site distance for $10 M_{\mathrm{w}} 7.9$ earthquake scenarios on the southern San Andreas fault (five rupture locations and two rupture directions) using the median stochastic source model. The predictions by the Campbell-Bozorgnia Next Generation Attenuation (NGA) relation are shown with circles. The shaded region corresponds to median \pm 1 standard deviation. The color version of this figure is available only in the electronic edition. 
(a)

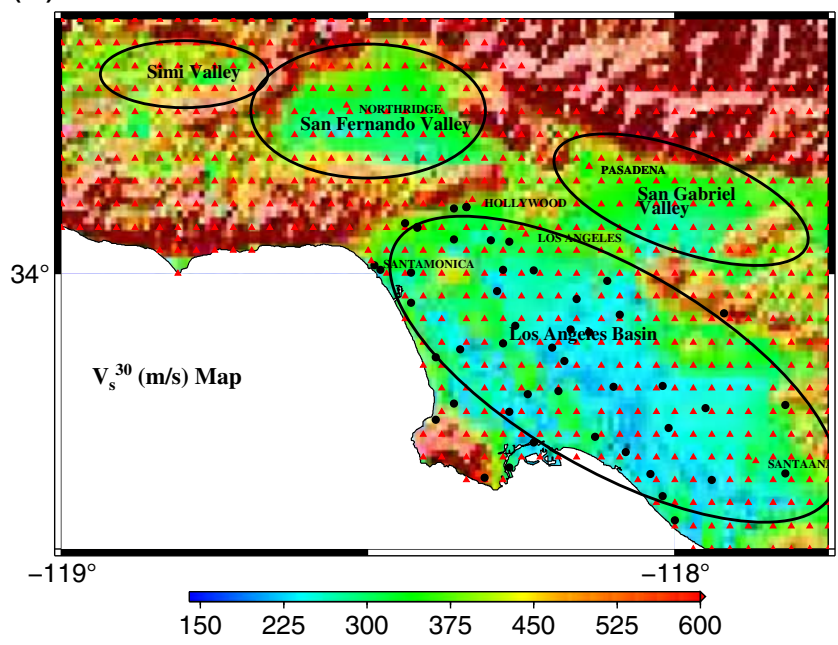

(b)

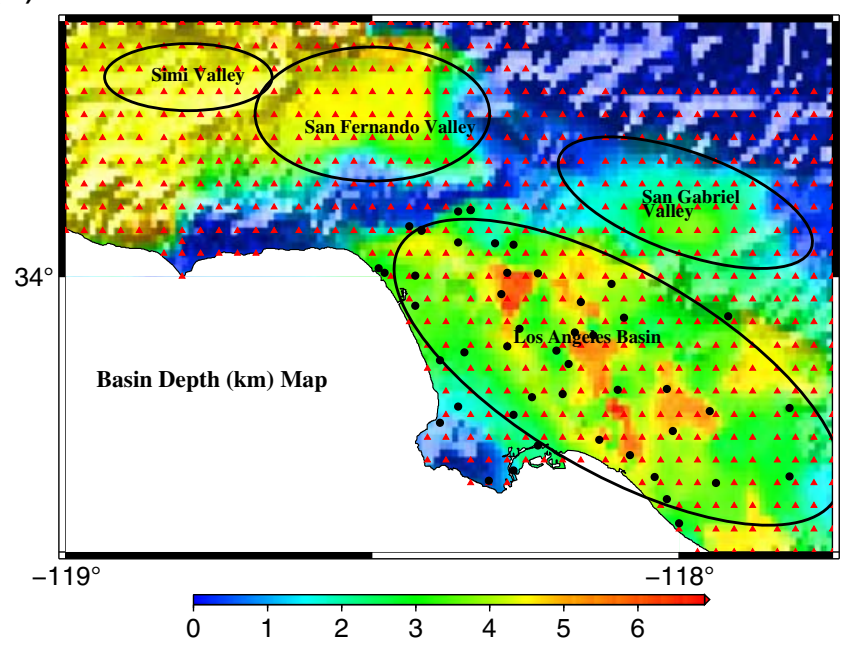

Figure 26. (a) $V_{S 30}(\mathrm{~m} / \mathrm{s})$ and (b) basin depth $(\mathrm{km})$ maps for southern California. The black circles correspond to 48 stations at which PGV and PGD values are computed using the Campbell-Bozorgnia attenuation relation for comparison against simulation predictions. The triangles indicate the geographical distribution of the 636 southern California sites where stochastic ground motions are computed. The ellipses identify the basins in southern California: Simi Valley, San Fernando Valley, San Gabriel Valley, and the Los Angeles basin. The color version of this figure is available only in the electronic edition.

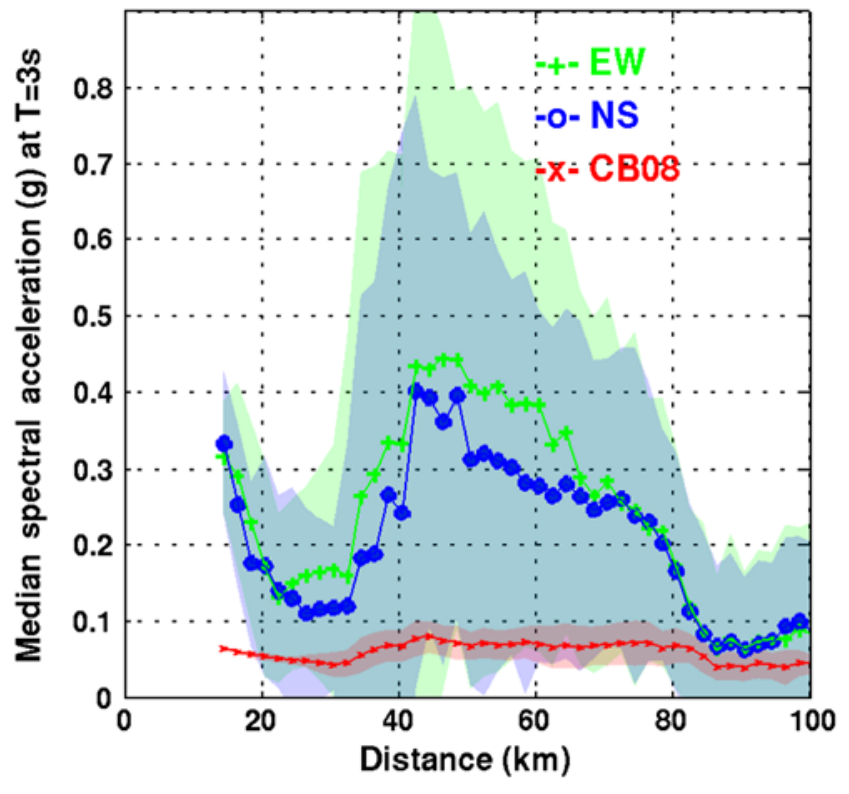

Figure 27. Spectral acceleration $(g)$ at $T=3 \mathrm{~s}\left(\mathrm{SA}^{3 s}\right)$ as a function of source-to-site distance for $10 M_{\mathrm{w}} 7.90$ earthquake scenarios on the southern San Andreas fault (five rupture locations and two rupture directions). The simulated east-west and the northsouth $\mathrm{SA}^{3 s}$ components at greater Los Angeles sites using the median stochastic source model are shown with + symbols and open circles, respectively. The predictions by the Campbell-Bozorgnia NGA relation are shown with $\times$ symbols. The shaded region corresponds to median \pm 1 standard deviation. The color version of this figure is available only in the electronic edition.

velocity histories. The median of this set of PGVs is used for the sensitivity analysis.

Figure 30 shows scatter plots of the median PGV as a function of the percentage of asperity area, the maximum rise time, and the percentage of the rupture propagating at sub-Rayleigh speeds. The histograms for each of these quantities are also shown. The following observations can be made: (1) there is a relatively low correlation (correlation coefficient $=-0.30$ ) between median PGV and percentage of asperity area. The reader should note here that a seismic source model with a single large asperity might have the same percentage of asperity area as one with several smaller asperities; however, the resulting ground motions from the two models may be significantly different. (2) A moderate correlation (correlation coefficient $=-0.57$ ) can be observed between the median PGV and the maximum rise time in the source model, with median PGV gradually declining with increasing values of maximum rise time. (3) An unexpected finding, however, is that the median PGV in the Los Angeles basin is generally larger when a greater proportion of the rupture propagates at sub-Rayleigh speeds and is smaller when a greater proportion of the rupture propagates at supershear speeds. Incidentally, Aagaard and Heaton (2004) reported a similar observation in their near-source groundmotion simulation. A high correlation coefficient of 0.74 is observed between median PGV and percentage of rupture propagating at sub-Rayleigh speed. (4) The mean of the median PGV at the 211 Los Angeles basin sites from all 50 of the 1857 Fort Tejon-like stochastic sources of $M_{\mathrm{w}}=7.9$ is $0.77 \mathrm{~m} / \mathrm{s}$, and the standard deviation is $0.26 \mathrm{~m} / \mathrm{s}$. In comparison, the corresponding mean and standard deviation of the PGV predicted by the Campbell and Bozorgnia (2008) NGA relation are 0.16 and $0.03 \mathrm{~m} / \mathrm{s}$, respectively. (5) The mean of the median PGD at the 211 southern California sites in the Los Angeles basin from all 50 stochastic sources of $M_{\mathrm{w}}=7.9$ is $1.09 \mathrm{~m}$, and the standard deviation is $0.40 \mathrm{~m}$. The corresponding mean and standard deviation of the PGD predicted by the 


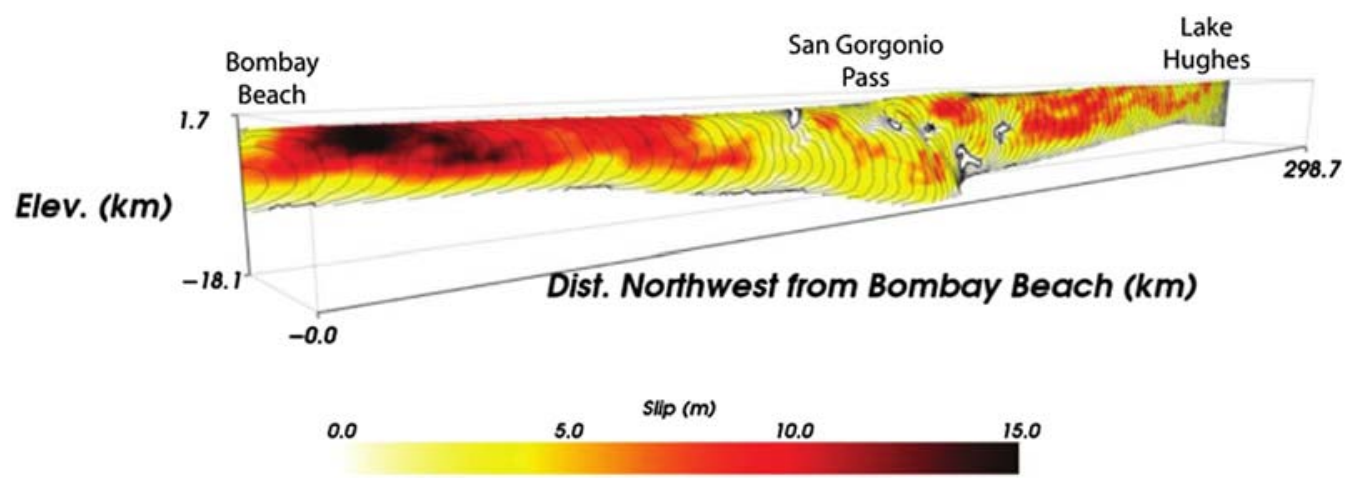

Figure 28. Slip (m) distribution and rupture time contours (1 s intervals) for an $M_{\mathrm{w}} 7.8$ earthquake of the ShakeOut earthquake source (Graves et al., 2011). The peak slip-rate for this source is $4.38 \mathrm{~m} / \mathrm{s}$. The color version of this figure is available only in the electronic edition.
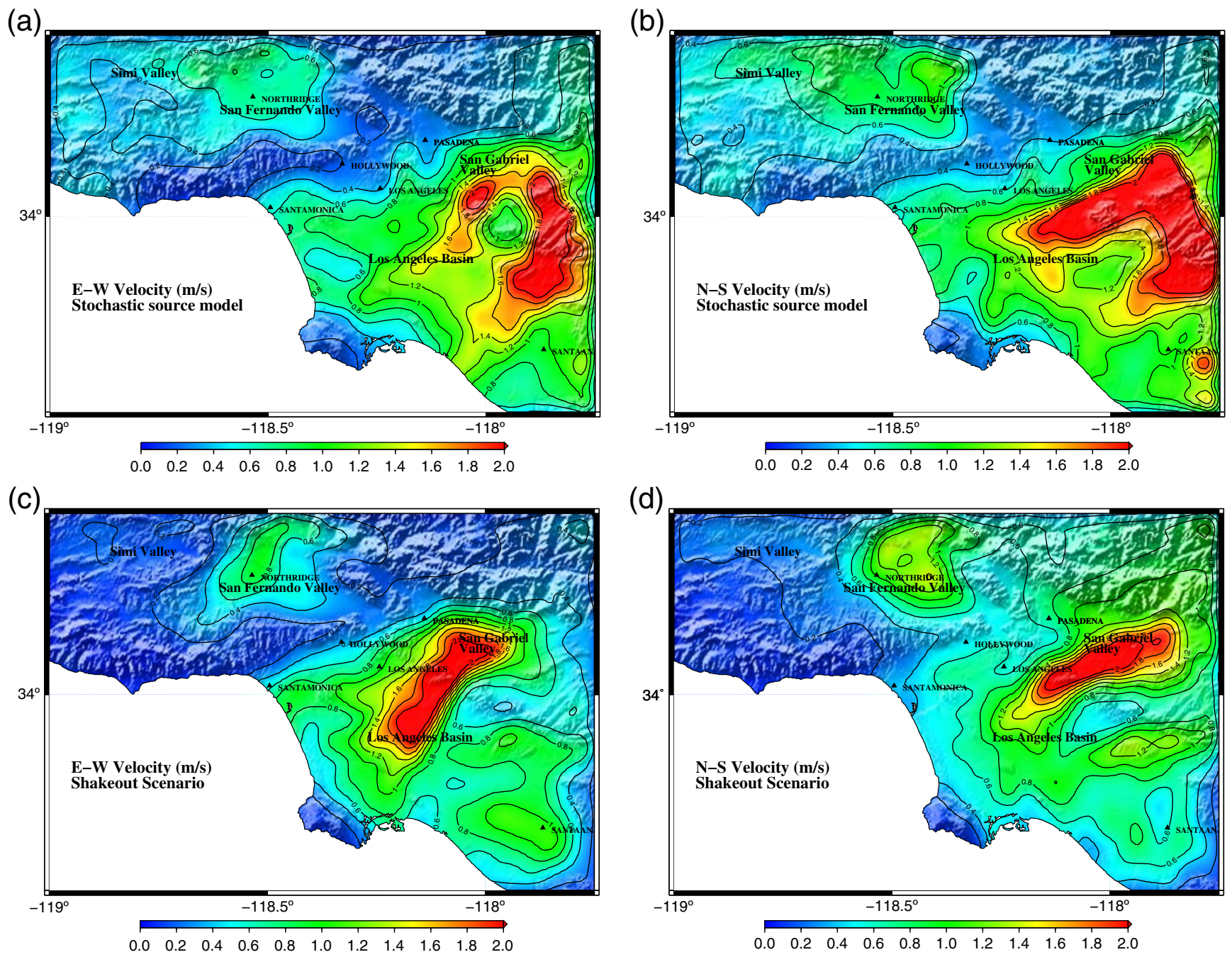

Figure 29. (a) East-west and (b) north-south component of PGV (m/s) simulated using the median stochastic source model with epicenter at Bombay Beach. (c) and (d) The corresponding PGV maps for the ShakeOut scenario. The color version of this figure is available only in the electronic edition.

Campbell-Bozorgnia NGA relation are 0.94 and $0.29 \mathrm{~m}$, respectively.

It is clear that although the mean and standard deviation of the PGD predicted by the attenuation relationship is in close agreement with that predicted by the simulations, the same cannot be said about PGV. It is important that this disagreement between NGA relations and the simulations is reconciled, because building codes utilize the NGA relations 

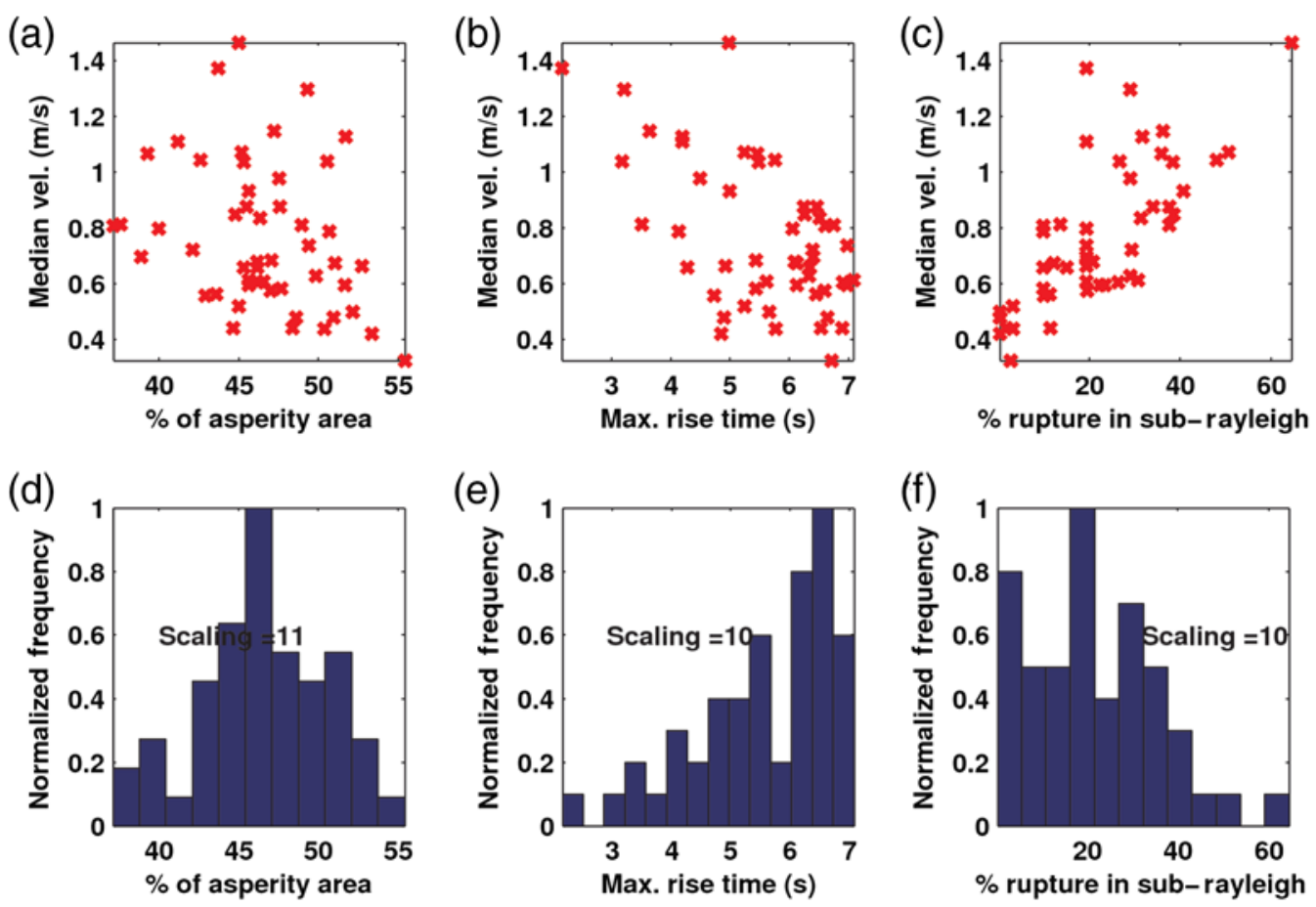

Figure 30. Results from simulating $50 M_{\mathrm{w}} 7.9$ north-to-south rupture scenarios on the San Andreas fault (similar to the 1857 Fort Tejon earthquake) using stochastic seismic source models. (a)-(c) The scatter plots of the median PGV in Los Angeles basin as a function of the percentage of asperity area relative to the fault area, the maximum rise time, and the percentage rupture propagating at sub-Rayleigh speeds. (d)-(f) The corresponding histograms for the 50 scenarios. The product of the listed scaling factor and the normalized histogram ordinate gives the parameter frequency. The color version of this figure is available only in the electronic edition.

to characterize seismic hazard for the design of buildings. This is especially critical for tall buildings because their response is quite sensitive to PGV (Krishnan and Muto, 2013).

To ensure that findings (2) and (3) are not limited to ground motions from earthquakes occurring at location 1 alone and instead hold more broadly, we plot the median PGV in the east-west and north-south directions at all sites in the greater Los Angeles area (not just the Los Angeles basin sites) from the 50 earthquakes described in the last section as a function of rise time (Fig. 31) and the percentage of the rupture propagating at the sub-Rayleigh speed of $0.87 V_{S}$ (Fig. 32). It is quite clear that the greater the percentage of rupture propagating at sub-Rayleigh speeds, the stronger are the ground motions. PGV drops marginally with increasing
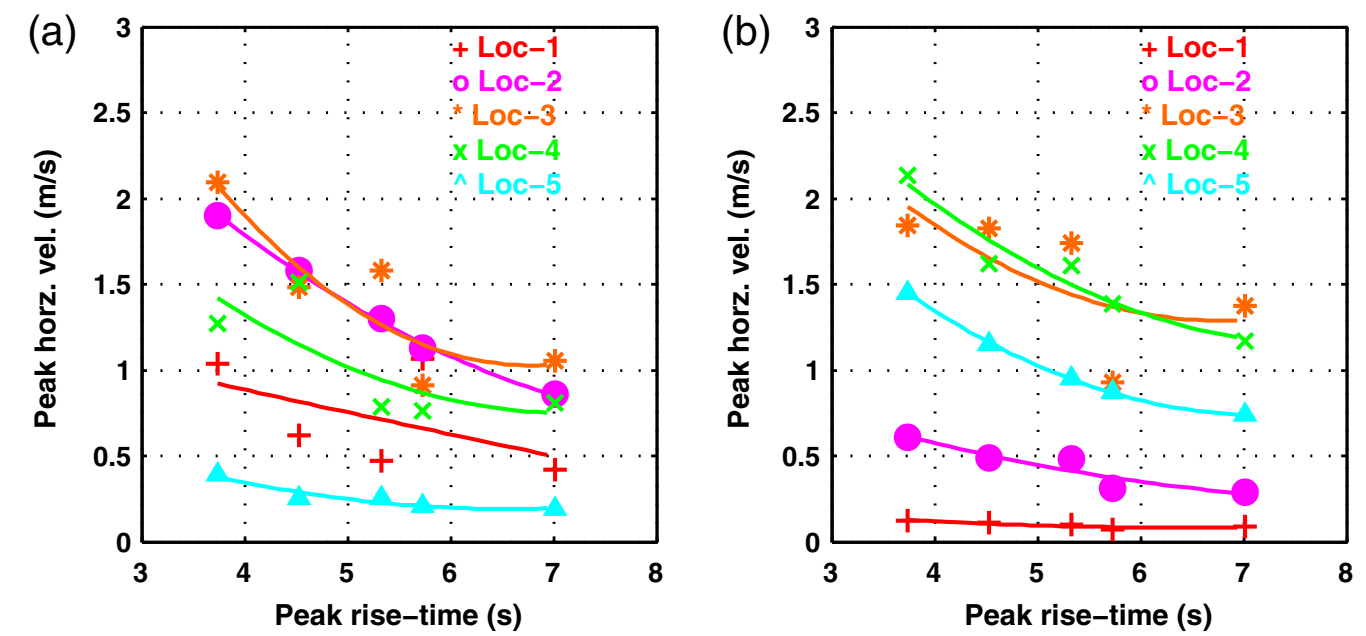

Figure 31. Median horizontal PGV (m/s) in southern California from a total of $50 M_{\mathrm{w}} 7.90$ earthquakes on the southern San Andreas fault (five source realizations $\times$ five rupture locations $\times$ two propagation directions) as a function of the rise time (s) for (a) north-to-south and (b) south-to-north propagating rupture. The color version of this figure is available only in the electronic edition. 

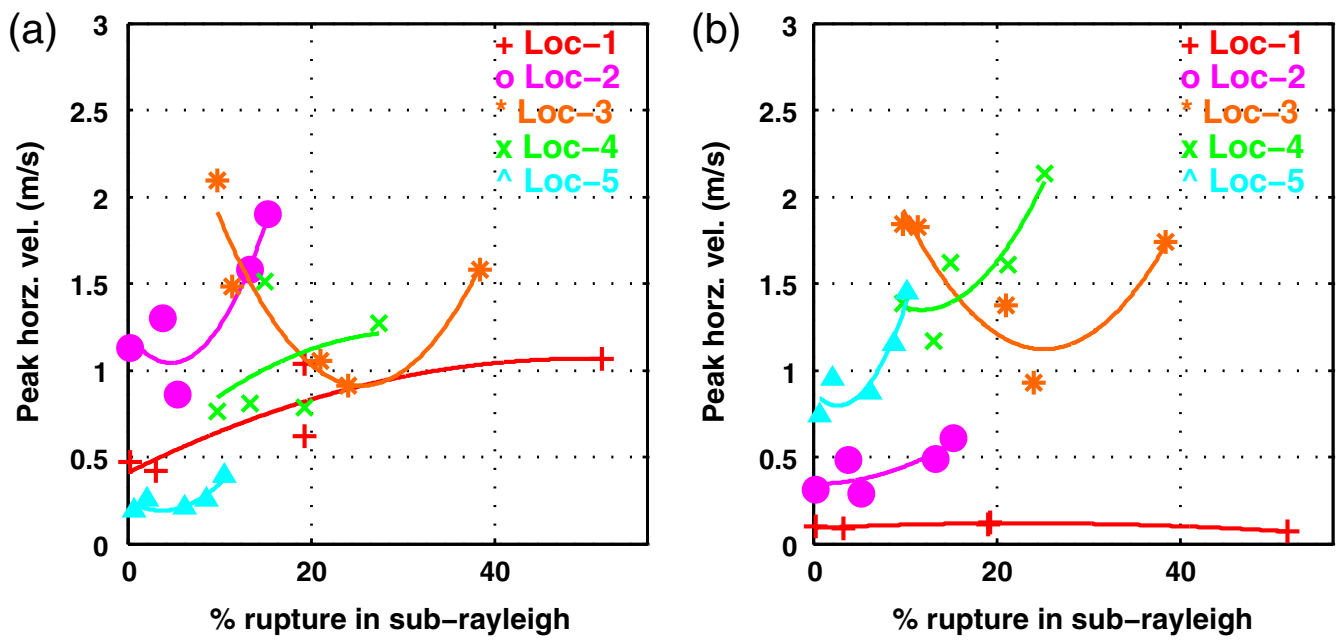

Figure 32. Median horizontal PGV (m/s) in southern California from a total of $50 M_{\mathrm{w}} 7.90$ earthquakes on the southern San Andreas fault (five source realizations $\times$ five rupture locations $\times$ two propagation directions) as a function of the percentage of rupture propagating at the sub-Rayleigh speed of $0.87 V_{S}$ for (a) north-to-south and (b) south-to-north propagating rupture. The color version of this figure is available only in the electronic edition.

rise time, although this anticorrelation is weaker than the correlation with respect to rupture speed. Findings (2) and (3) thus appear to hold true for all rupture locations and all southern California sites (when considered collectively). However, we are not sure whether the number of source models used in the sensitivity study are enough to capture the variability of sources on a fault such as the San Andreas. Further studies are needed to quantify the sample size necessary to ensure statistical significance.

\section{Discussion}

The recursive division algorithm outlined here can be implemented for any strike-slip fault in the world, given good estimates of principal stress orientations. Principal stress orientation data is currently available for most major fault systems worldwide (see Data and Resources), although the quality of the data may not be uniformly good. In the absence of such data an assumption would have to be made on the rupture speed in order for this algorithm to be used (e.g., a constant rupture speed of, say, $0.8 V_{S}$, across the fault). In making this assumption, we must consider the finding that the greater the percentage of the rupture propagating at subRayleigh speeds, the stronger is the resulting ground motion. The presented algorithm augments known aspects of seismic sources from finite-source inversions with observations from laboratory earthquakes to model kinematic parameters of strike-slip sources, thus incorporating physics of the rupture process as we best know it. There are three distinguishing features of the recursive division algorithm that sets it apart from other existing methodologies:

First, when generating stochastic slip distributions in the spatial domain, the recursive division algorithm deviates from the common approach of defining a 2D PSD function that usually decays with increasing wavenumber and in- verting it back into the spatial domain to generate the slip distribution. A subsequent check is made to ensure that the slip power spectrum decays as a function of the wavenumber in accordance with a power law for which the exponent is between 2 and 4, the range of values observed in finitesource inversions of past earthquakes. Allowing such a range for this exponent rather than imposing a fixed value (as is done in existing methods) would likely produce a more diverse set of seismic source models, more closely emulating the broad spectrum of seismic sources inferred from earthquake data. In addition, this approach would produce distinct power spectra of slip along the length and the depth of the fault. One questionable feature of our algorithm is that it prescribes smoothly varying slip across kinks and bends of nonplanar faults. The effects of this feature of the resulting stochastic source models need to be studied in the future.

Second, based on the observation in laboratory earthquakes that rupture speed is dependent upon initial stress conditions on the fault, the recursive division algorithm uses initial stress to judge whether rupture proceeds at sub-Rayleigh speeds or at supershear speeds. Rather than assigning a constant average rupture propagation speed, the algorithm assigns sub-Rayleigh and supershear propagation speeds of $0.87 V_{S}$ and $1.67 V_{S}$, respectively, as observed in the laboratory. Thus, the resulting kinematic source models are physics-based and more realistic. Some existing models do specify a varying slip-proportional rupture speed. However, dynamic rupture simulations have not conclusively shown this to be true.

It should be mentioned that calculating the initial stress on the fault is a nontrivial problem, especially in the face of limited data. The key assumption that goes into the determination of the normal and shear stresses using the principal stress orientations along the fault is that the fault is in a critical state and that the pore pressure in the crust surrounding the fault is hydrostatic. This assumption is based on in situ 
measurements, core samples, and inferences from seismicity. Given that the measurements are made at shallow depths of the Earth's crust, it is an open question whether this assumption holds true over the entire seismogenic depth of the fault. Nevertheless, in the absence of evidence to the contrary, it is assumed that the stress across the depth of the fault is uniform. This results in rupture speeds that are variable along fault length but constant along fault depth.

In the third feature, both laboratory earthquakes and dynamic rupture simulations indicate that there exists a correlation between slip and rise time. Empirical relations characterizing this correlation that have been determined from dynamic rupture simulations can be quite sensitive to the choice of parameters used in the simulations. Accordingly, slip-to-rise-time ratios from the laboratory earthquakes are directly used to characterize the rise times (and hence slip velocity) in the recursive division algorithm. The slip-to-risetime ratio (i.e., slip velocity) is assumed to be constant for a given stochastic source realization. The maximum rise time observed in finite-source inversions of past earthquakes is used to constrain rise times in the algorithm as well.

The extension and applicability of laboratory observations to the real Earth is still an open question. The issue of scaling is far from resolved. We must reiterate, however, that the self-similarity assumption for the slip-to-rise-time ratio between the laboratory scale and the Earth scale is as plausible (or not) as the self-similarity assumptions on initial stresses on faults made in dynamic rupture propagation simulations. In this work, we studied long-period ground motions at distances $>15 \mathrm{~km}$ or so. Long-period ground motion at these distances may not be sensitive to the detailed shape of the source time function, so the use of triangular slip velocity-time functions in our stochastic sources may be acceptable. However, more realistic (dynamically compatible) Kostrov-type or modified Yoffe-type source time functions (Tinti et al., 2005) may be needed for broadband and/or near-source ground-motion simulations.

The characterization of the underlying probability distributions of earthquake source parameters (and/or their correlations) in the proposed approach may possibly be improved by incorporating statistics from dynamic rupture simulations (rather than from finite source inversions in the case of slip, for instance). Such an approach is used by pseudodynamic stochastic rupture model generators (e.g., Song and Somerville, 2010; Mena et al., 2012; Song et al., 2014; Trugman and Dunham, 2014). They typically represent final slip, rupture speed, and slip rate as spatial random fields that are statistically characterized (and/or correlated) by synthetic data from dynamic rupture simulations. Because dynamic models are physically self-consistent, they may be able to better characterize the relationship between earthquake source parameters. However, they too suffer from a lack of knowledge of the spatial heterogeneity of the background stress field and the frictional failure law for the fault. As more data to better constrain these aspects become available, our algo- rithm may be adapted to incorporate earthquake source parameter statistics from dynamic rupture simulations.

\section{Conclusions and Ongoing Work}

A recursive division algorithm for generating stochastic source models of $M_{\mathrm{w}}=6.0$ to 8.0 strike-slip earthquakes is presented. The algorithm uses observations from laboratory earthquakes to augment the known physics of earthquake ruptures from finite-source inversions of past earthquakes. It is validated through a statistical comparison of long-period ( $2 \mathrm{~s}$ and higher) ground motions generated by stochastic source models and finite-source models of past earthquakes of equivalent magnitude. Its application to several $M_{\mathrm{w}} 7.9$ earthquake simulations at different locations on the southern San Andreas fault has yielded interesting results. First (not surprisingly), the location of strong ground motions is closely related to the location, size, and strength of slip asperities on the source. Second, ground-motion intensities are higher when a greater proportion of the rupture propagates at sub-Rayleigh speeds, whereas the intensities are lower when a greater proportion of the rupture propagates at supershear speeds. Third, ground-motion intensities in the Los Angeles basin are lower when the peak rise time in the source is higher, although this anticorrelation is not as strong as the correlation with the percentage of rupture propagating at subRayleigh rupture speeds. Fourth, the median PGDs (and the PGD variability) from the simulations as a function of sourceto-site distance agree well with predictions by the CampbellBozorgnia NGA relation. Fifth, the median PGVs (and the PGV variability) from the simulations as a function of source-to-site distance are three to six times higher than that predicted by the Campbell-Bozorgnia NGA relation. It is imperative that the differences in the simulations and the NGA predictions be reconciled to ensure that seismic-hazard maps based on the NGA relations are credible.

\section{Data and Resources}

The database of global finite-source rupture models of past earthquakes was searched using http://www.seismo.ethz .ch/static/srcmod/Events.html (last updated 23 July 2007; last accessed September 2014). The World Stress Map project database was accessed using http://dc-app3-14.gfz-potsdam.de/ index.html (last updated August 2009; last accessed October 2014). The ground-motion plots were made using Generic Mapping Tools v.4.5.7, available at http://gmt.soest.hawaii. edu/projects/gmt (last accessed October 2014).

\section{Acknowledgments}

We acknowledge the financial support from the U.S. National Science Foundation-Civil, Mechanical and Manufacturing Innovation (NSF-CMMI Award Number 0926962) and the U.S. Geological Survey (USGS) National Earthquake Hazards Reduction Program (NEHRP Award Number G09AP00063). We thank Thomas Heaton (Caltech), Jean Paul Ampuero (Caltech), Dimitri Komatitsch (Centre National de la Recherche Scientifique /University of Aix-Marseille), Martin Mai (King Abdullah University of Sci- 
ence and Technology [KAUST]), Rob Graves (USGS), and Chen Ji (University of California Santa Barbara) for offering valuable insights into various aspects of source physics and seismic-wave propagation. We thank Chen $\mathrm{Ji}$ and Martin Mai for providing us with finite-source inversion models of past earthquakes. We thank Ares Rosakis and Nadia Lapusta for providing us with data from laboratory earthquakes. We are grateful to members of the Tromp research groups at Princeton (current) and Caltech, the Shaw Research Group at Harvard for the continued development of SPECFEM3D, and Southern California Earthquake Center (SCEC) Community Velocity Model-Harvard (CVM-H) for free use by the research community at large. We thank the reviewers and Associate Editor Luis Angel Dalguer for their valuable insights. The authors would also like to acknowledge the central role of the SCEC in advancing earth system science in southern California, directly benefiting many elements of this study.

\section{References}

Aagaard, B. T., and T. Heaton (2004). Near-source ground motions from simulations of sustained intersonic and supersonic fault ruptures, Bull. Seismol. Soc. Am. 94, 2064-2078.

Aagaard, B. T., R. W. Graves, A. Rodgers, T. M. Brocher, R. W. Simpson, D. Dreger, N. A. Petersson, S. C. Larsen, S. Ma, and R. C. Jachens (2010). Ground-motion modeling of Hayward fault scenario earthquakes, part II: Simulation of long-period and broadband ground motions, Bull. Seismol. Soc. Am. 100, no. 6, 2945-2977.

Aagaard, B. T., R. W. Graves, D. P. Schwartz, D. A. Ponce, and R. W. Graymer (2010). Ground-motion modeling of Hayward fault scenario earthquakes, part I: Construction of the suite of scenarios, Bull. Seismol. Soc. Am. 100, no. 6, 2927-2944.

Andrews, D. (1976). Rupture velocity of plane strain shear cracks, J. Geophys. Res. 81, no. 32, 5679-5687.

Andrews, D., and M. Barall (2011). Specifying initial stress for dynamic heterogenous earthquake source models, Bull. Seismol. Soc. Am. 101, no. 5, 2408-2417.

Archuleta, R. (1984). A faulting model for the 1979 Imperial Valley earthquake, J. Geophys. Res. 89, 4559-4585.

Baker, J. W., N. Luco, N. A. Abrahamson, R. W. Graves, P. J. Maechling, and K. B. Olsen (2014). Engineering uses of physics-based ground motion simulations, in Proceedings of the Tenth US Conference on Earthquake Engineering, Anchorage, Alaska, 21-25 July 2014.

Baumann, C., and L. A. Dalguer (2014). Evaluating the compatibility of dynamic rupture-based synthetic ground motion with empirical ground-motion prediction equation, Bull. Seismol. Soc. Am. 104, no. $2,634-652$.

Bhat, H. S., R. Dmowska, G. C. P. King, Y. Klinger, and J. R. Rice (2007) Off-fault damage patterns due to supershear ruptures with application to the $2001 M_{\mathrm{w}} 8.1$ Kokoxili (Kunlun) Tibet earthquake, J. Geophys. Res. 112, no. B06301, doi: 10.1029/2006JB004425.

Bielak, J., R. W. Graves, K. B. Olsen, R. Taborda, L. Ramirez-Guzman, S. M. Day, G. P. Ely, D. Roten, T. H. Jordan, P. J. Maechling, et al. (2010). The ShakeOut earthquake scenario: Verification of three simulation sets, Geophys. J. Int. 180, no. 1, 375-404.

Bizzarri, A. (2011). On the deterministic description of earthquakes, Rev. Geophys. 49, 3002, doi: 10.1029/2011RG000356.

Bouchon, M., and M. Vallée (2003). Observation of long supershear rupture during the magnitude 8.1 Kunlunshan earthquake, Science 301, no. $5634,824-826$.

Bouchon, M., M. Toksoz, H. Karabulut, M. Bouin, M. Dietrich, M. Aktar, and M. Edie (2002). Space and time evolution of rupture and faulting during the 1999 Izmit (Turkey) earthquake, Bull. Seismol. Soc. Am. 92, no. 1, 256-266.

Brune, J. (1970). Tectonic stress and spectra of seismic shear waves from earthquakes, J. Geophys. Res. 75, no. 26, 4997-5009.

Burridge, R. (1973). Admissible speeds for plane-strain self-similar shear cracks with friction but lacking cohesion, Geophys. J. Roy. Astron. Soc. 35, no. 4, 439-455.
Campbell, K. W., and Y. Bozorgnia (2008). NGA ground motion model for the geometric mean horizontal component of PGA, PGV, PGD and 5\% damped linear elastic response spectra for periods ranging from 0.01 to 10 s, Earthq. Spectra 24, no. 1, 139.

Cotton, F., and M. Campillo (1995). Frequency-domain inversion of strong motions-Application to the 1992 Landers earthquake, J. Geophys. Res. 100, 3961-3975.

Cui, Y., K. B. Olsen, T. H. Jordan, K. Lee, J. Zhou, P. Small, D. Roten, G. Ely, D. K. Panda, A. Chourasia, et al. (2010). Scalable earthquake simulation on petascale supercomputers, in 2010 International Conference for High Performance Computing, Networking, Storage and Analysis (SC), New Orleans, Louisiana, 13-19 November 2010, 1-20.

Dalguer, L. A., H. Miyake, S. M. Day, and K. Irikura (2008). Surface rupturing and buried dynamic-rupture models calibrated with statistical observations of past earthquakes, Bull. Seismol. Soc. Am. 98, no. 3, $1147-1161$.

Das, S. (2010). Earthquake supershear rupture speeds: Preface, Tectonophysics 493, 213-215.

Di Toro, G., D. L. Goldsby, and T. E. Tullis (2004). Friction falls towards zero in quartz rock as slip velocity approaches seismic rates, Nature 427, no. 6973, 436-439.

Dunham, E. M., and R. J. Archuleta (2004). Evidence for a supershear transient during the 2002 Denali fault earthquake, Bull. Seismol. Soc. Am. 94, no. 6B, S256-S258.

Ely, G. P., S. M. Day, and J.-B. Minster (2010). Dynamic rupture models for the southern San Andreas fault, Bull. Seismol. Soc. Am. 100, no. 1, 131-150.

Fialko, Y., D. Sandwell, M. Simons, and P. Rosen (2005). Three-dimensional deformation caused by the Bam, Iran, earthquake and the origin of shallow slip deficit, Nature 435, no. 7040, 295-299.

Frankel, A. (2004). Rupture process of the M7.9 Denali fault, Alaska, earthquake: Subevents, directivity, and scaling of high-frequency ground motions, Bull. Seismol. Soc. Am. 94, no. 6B, S234-S255.

Goldsby, D., and T. Tullis (2002). Low frictional strength of quartz rocks at subseismic slip rates, Geophys. Res. Lett. 29, no. 17, 25-1-25-4.

Graves, R. W., and A. Pitarka (2010). Broadband ground-motion simulation using a hybrid approach, Bull. Seismol. Soc. Am. 100, no. 5A, 2095-2123.

Graves, R. W., B. T. Aagaard, and K. W. Hudnut (2011). The ShakeOut earthquake source and ground motion simulations, Earthq. Spectra 27, no. 2, 273-291

Guatteri, M., P. M. Mai, and G. C. Beroza (2004). A pseudo-dynamic approximation to dynamic rupture models for strong ground motion prediction, Bull. Seismol. Soc. Am. 94, no. 6, 2051-2063

Hanks, T., and W. H. Bakun (2002). A bilinear source-scaling model for M-log A observations of continental earthquakes, Bull. Seismol. Soc. Am. 92, no. 5, 1841-1846.

Hanks, T. C., and W. H. Bakun (2008). M-logA observations for recent large earthquakes, Bull. Seismol. Soc. Am. 98, no. 1, 490-494.

Harris, R., M. Barall, R. Archuleta, E. Dunham, B. Aagaard, J. Ampuero, H. Bhat, V. Cruz-Atienza, L. Dalguer, P. Dawson, et al. (2009). The SCEC/USGS dynamic earthquake rupture code verification exercise, Seismol. Res. Lett. 80, no. 1, 119-126.

Hartzell, S., S. Harmsen, A. Frankel, and S. Larsen (1999). Calculation of broadband time histories of ground motion: Comparison of methods and validation using strong-ground motion from the 1994 Northridge earthquake, Bull. Seismol. Soc. Am. 89, no. 6, 1484-1504.

Hartzell, S., P. Liu, and C. Mendoza (1996). The 1994 Northridge, California, earthquake: Investigation of rupture velocity, risetime, and highfrequency radiation, J. Geophys. Res. 101, 20,091-20,108.

Heidbach, O., M. Tingay, A. Barth, J. Reinecker, D. Kurfeß, and B. Müller (2008). The World Stress Map Database Release 2008, doi: 10.1594/ GFZ.WSM.Rel2008.

Ide, S., and M. Takeo (1997). Determination of constitutive relations of fault slip based on seismic wave analysis, J. Geophys. Res. 102, no. B, 27379-27391.

Ji, C. (2004). Slip history the 2004 ( $M_{\mathrm{w}}$ 5.9) Parkfield earthquake (singleplane model), http://www.tectonics.caltech.edu/slip_history/2004_ca/ parkfield2.html (last accessed December 2014). 
Kohler, M., H. Magistrale, and R. Clayton (2003). Mantle heterogeneities and the SCEC three-dimensional seismic velocity model version 3 , Bull. Seismol. Soc. Am. 93, no. 2, 757-774.

Komatitsch, D., and J. Tromp (1999). Introduction to the spectral element method for three-dimensional seismic wave propagation, Geophys. $J$. Int. 139, no. 3, 806-822.

Krishnan, S., and M. Muto (2013). Sensitivity of the earthquake response of tall steel moment frame buildings to ground motion features, J. Earthq. Eng. 17, no. 5, 673-698.

Krishnan, S., C. Ji, D. Komatitsch, and J. Tromp (2006). Case studies of damage to tall steel moment-frame buildings in southern California during large San Andreas earthquakes, Bull. Seismol. Soc. Am. 96, no. $4 \mathrm{~A}, 1523$.

Krishnan, S., M. Muto, R. Mourhatch, A. B. Bjornsson, and H. Siriki (2011). Rupture-to-rafters simulations: Unifying science and engineering for earthquake hazard mitigation, IEEE Comput. Sci. Eng. Mag. (Special Issue on Earthquake Engineering Simulation) 13, no. 4, 28-43.

Lavallée, D., P. Liu, and R. J. Archuleta (2006). Stochastic model of heterogeneity in earthquake slip spatial distributions, Geophys. J. Int. 165, no. $2,622-640$.

Liu, P., R. J. Archuleta, and S. H. Hartzell (2006). Prediction of broadband ground-motion time histories: Hybrid low/high-frequency method with correlated random source parameters, Bull. Seismol. Soc. Am. 96, no. 6, 2118-2130.

$\mathrm{Lu}, \mathrm{X}$. (2009). Combined experimental and numerical study of spontaneous dynamic rupture on frictional interfaces, Ph.D. Thesis, California Institute of Technology, $180 \mathrm{pp}$.

Lu, X., A. J. Rosakis, and N. Lapusta (2010). Rupture modes in laboratory earthquakes: Effect of fault prestress and nucleation conditions, J. Geophys. Res. 115, no. B12302, doi: 10.1029/2009JB006833.

Madariaga, R., and K. B. Olsen (2002). Earthquake dynamics, in International Handbook of Earthquake and Engineering Seismology, P. C. J. William, H. K. Lee, H. Kanamori, and C. Kisslinger (Editors), Vol. 81, International Geophysics, chapter 12, Part A, Academic Press, San Diego, California, 175 pp.

Mai, P., and G. Beroza (2002). A spatial random field model to characterize complexity in earthquake slip, J. Geophys. Res. 107, doi: 10.1029/ 2001JB000588.

Mello, M., H. S. Bhat, A. J. Rosakis, and H. Kanamori (2010). Identifying the unique ground motion signatures of supershear earthquakes: Theory and experiments, Tectonophysics 493, 297-326.

Mena, B., L. A. Dalguer, and P. M. Mai (2012). Pseudodynamic source characterization for strike-slip faulting including stress heterogeneity and super-shear ruptures, Bull. Seismol. Soc. Am. 102, no. 4, 1654-1680.

Nielsen, S., and R. Madariaga (2003). On the self-healing fracture mode, Bull. Seismol. Soc. Am. 93, no. 6, 2375-2388.

Olsen, K. B., and J. E. Mayhew (2010). Goodness-of-fit criteria for broadband synthetic seismograms, with application to the $2008 M_{\mathrm{w}} 5.4$ Chino Hills, California, earthquake, Seismol. Res. Lett. 81, no. 5, 715-723.

Olsen, K. B., S. Day, L. Dalguer, J. Mayhew, Y. Cui, J. Zhu, V. Cruz-Atienza, D. Roten, P. Maechling, T. Jordan, et al. (2009). ShakeOut-D: Ground motion estimates using an ensemble of large earthquakes on the southern San Andreas fault with spontaneous rupture propagation, Geophys. Res. Lett. 36, L04303, doi: 10.1029/2008GL036832.

Olsen, K. B., S. M. Day, J. B. Minster, Y. Cui, A. Chourasia, D. Okaya, P. Maechling, and T. Jordan (2008). Terashake2: Spontaneous rupture simulations of $M_{\mathrm{w}} 7.7$ earthquakes on the southern San Andreas fault, Bull. Seismol. Soc. Am. 98, no. 3, 1162-1185.

Plesch, A., C. Tape, J. Graves, P. Small, G. Ely, and J. Shaw (2011). Updates for the CVM-H including new representations of the offshore Santa Maria and San Bernardino basin and a new Moho surface, in 2011 Southern California Earthquake Center Annual Meeting, Proceedings and Abstracts, Palm Springs, California 11-14 September 2011, Vol. 21.

Rosakis, A., O. Samudrala, and D. Coker (1999). Cracks faster than the shear wave speed, Science 284, no. 5418, 1337-1340.
Rosakis, A., K. Xia, G. Lykotrafitis, and H. Kanamori (2007). Dynamic shear rupture in frictional interfaces: Speeds, directionality and modes, Treatise in Geophysics, Elsevier, Amsterdam, The Netherlands.

Schmedes, J., R. J. Archuleta, and D. Lavallée (2010). Correlation of earthquake source parameters inferred from dynamic rupture simulations, J. Geophys. Res. 115, no. B03304, doi: 10.1029/2009JB006689.

Shi, Z., and S. M. Day (2013). Rupture dynamics and ground motion from 3-D rough-fault simulations, J. Geophys. Res. 118, no. 3, 1122-1141.

Somerville, P., K. Irikura, R. Graves, S. Sawada, D. Wald, N. Abrahamson, Y. Iwasaki, T. Kagawa, N. Smith, and A. Kowada (1999). Characterizing earthquake rupture models for the prediction of strong ground motion, Seismol. Res. Lett. 70, 59-80.

Song, S. G., and P. Somerville (2010). Physics-based earthquake source characterization and modeling with geostatistics, Bull. Seismol. Soc. Am. 100, no. 2, 482-496.

Song, S. G., L. A. Dalguer, and P. M. Mai (2014). Pseudo-dynamic source modelling with 1-point and 2-point statistics of earthquake source parameters, Geophys. J. Int. 196, no. 3, 1770-1786.

Tinti, E., E. Fukuyama, A. Piatanesi, and M. Cocco (2005). A kinematic source-time function compatible with earthquake dynamics, Bull. Seismol. Soc. Am. 95, no. 4, 1211-1223.

Townend, J. (2006). What do faults feel? Observational constraints on the stresses acting on seismogenic faults, Geophys. Monogr. Ser. 170, 313-327.

Townend, J., and M. Zoback (2000). How faulting keeps the crust strong, Geology 28, no. 5, 399.

Townend, J., and M. Zoback (2004). Regional tectonic stress near the San Andreas fault in central and southern California, Geophys. Res. Lett. 31, no. 15 , doi: $10.1029 / 2003$ GL018918.

Trugman, D. T., and E. M. Dunham (2014). A 2D pseudodynamic rupture model generator for earthquakes on geometrically complex faults, Bull. Seismol. Soc. Am. 104, no. 1, 95-112.

Wald, D. J., and T. Allen (2007). Topographic slope as a proxy for seismic site conditions and amplification, Bull. Seismol. Soc. Am. 97, no. 5, 1379-1395.

Zeng, Y., J. Anderson, and G. Yu (1994). A composite source model for computing realistic synthetic strong ground motions, Geophys. Res. Lett. 21, no. 8, 725-728.

Zoback, M., and J. Townend (2001). Implications of hydrostatic pore pressures and high crustal strength for the deformation of intraplate lithosphere, Tectonophysics 336, no. 1, 19-30.

California Institute of Technology

1200 E. California Boulevard, MC 104-44

Pasadena, California 91125

hemanth@caltech.edu

krishnan@caltech.edu

(H.S., S.K.)

Institut de Physique du Globe de Paris

Tectonique et mécanique de la lithosphère \& Sismologie

1 rue Jussieu

Bureau 204

75238 Paris Cedex 05

France

harshasbhat@gmail.com

(H.S.B.)

Module Engineering Technologist, ATTD

Intel Corporation

$5000 \mathrm{~W}$ Chandler Boulevard

Chandler, Arizona 85226

xiaolu.galcit@gmail.com

(X.L.)

Manuscript received 21 April 2014; Published Online 28 July 2015 